\title{
The Hidden Costs of Strategic Opacity*
}

\author{
Ana Babus \\ Maryam Farboodi \\ Washington University in St. Louis \& CEPR \\ MIT Sloan
}

November 2018

\begin{abstract}
We explore a model in which banks strategically hold interconnected and opaque portfolios, despite increasing the likelihood they are subject to financial crises. In our framework, banks choose their degree of exposure to other banks to influence how investors can use their information. In equilibrium banks choose portfolios which are neither fully opaque, nor fully transparent. However, their portfolios are interconnected beyond what is beneficial for diversification purposes. Banks can create a degree of opacity that decreases welfare, and makes bank crises more likely. Our model is suggestive about the implications of asset securitization, as well as government bailouts.
\end{abstract}

JEL Classifications: G14, G21, D82, D43

Keywords: opacity; banking crises; interdependent portfolios

*Email addresses: anababus@wustl.edu, farboodi@mit.edu. We are grateful to Philip Bond, Douglas Diamond, Thierry Foucault, Martin Oehmke, Cecilia Parlatore, Anatoli Segura, Alireza Tahbaz-Salehi, Victoria Vanasco, and numerous seminar and conference participants for useful comments. 


\section{Introduction}

Bank interconnectedness has increased dramatically in the past few decades both in the US and worldwide. A substantial fraction of connections are represented by overlapping portfolio exposures across financial institutions. For instance, at its peak asset securitization alone contributed $\$ 1.5$ trillion to the increase in the interdependence of banks' portfolios. Such connections render the financial system inherently opaque. The lack of transparency plays a significant role in shaping market participants' beliefs, which have been a key ingredient in the unfolding of the global financial crisis. But how costly is it for banks to raise funds when investors are not able evaluate the web of interconnections between them?

In this paper we explore a model in which banks purposefully create opacity for their investors, by choosing interconnected portfolios. Even as they compete to attract investors, banks are able to raise funds at a negative premium for holding opaque portfolios. Moreover, banks decide on portfolio allocations which expose investors to uncertainty about banks' counterparty risk, and lead to an increase in the probability of banking crises. In other words, banks sow the seeds for crises in order to boost profits while they operate.

We consider a simple three-period model with two banks and two investors. Each bank has access to a risky investment project. A bank can decide to swap a fraction of its project with the other bank. If banks exchange a positive share of their projects, their portfolios are interdependent. Otherwise, their portfolios are independent.

To finance the projects, banks need to raise funds from investors. We consider an economy where banks compete to attract funds from investors by promising them a long-term debt contract that maximizes investors' expected payoff. However, each investor has the option to liquidate the contract prematurely against an outside redemption value. The outside redemption value represents the investors' reservation value, and can be interpreted as a reduced form of secondary market liquidity in the tradition of Allen and Gale (1994), and more recently of Dewatripont and Tirole (2018). If the investor liquidates early, the bank receives zero. If the investor continues the contract, the bank repays him the face value of debt if the return of the portfolio is sufficiently high. Otherwise the bank defaults. The bank is the residual claimant on the return of the portfolio.

In this environment we consider two frictions. First, we assume that investors can use their 
funds to finance only one bank. The interpretation is that each bank needs to be monitored, as in Diamond (1984), and monitoring two banks is prohibitively expensive. This does not precludes the banks to offer competitive debt contracts, just as in a standard Bertrand-Nash setting studied by Matutes and Vives (1996) and estimated empirically by Egan, Hortacsu and Matvos (2018).

Second, we consider an information friction between banks and investors. We assume that each investor receives information that perfectly reveals the return of his bank's project, and it is completely uninformative about the other bank's project. Thus, if banks swap a fraction of their projects, the signal the investors receive is less informative about the success of their bank's overall portfolio. This can be, for instance, because banks specialize in lending to different industries and investors learn about their bank's industry, in the spirit of rational inattention. While empirical work on how much information investors decide to process is limited, evidence from international financial markets suggests that agents do indeed allocate more attention to countries whose assets make up a greater share of their portfolios (Mondria, $\mathrm{Wu}$, and Zhang, 2010). Based on the information they receive, investors can decide to liquidate their debt contract before it matures, leading to a financial crisis. The degree of opacity of the financial system is then given by the degree of interconnectedness of banks' portfolios.

Our main focus is on whether banks choose opaque portfolios, whether opacity is an efficient outcome, and what it implies about the frequency of financial crises.

We obtain three sets of results. The first set of results characterizes the portfolio allocation that banks hold in equilibrium and the implications for welfare. Our main finding is that banks often hold inefficiently opaque portfolios. ${ }^{1}$ In particular, we show that in equilibrium, an intermediate level of opacity typically dominates both full transparency, as well complete opacity. In addition, we find that in equilibrium portfolio allocations are welfare reducing, unless investors' early redemption option is either too low or too high. We argue that unlike the traditional view on securitization, which suggests that banks sell securitized assets to benefit from an existing informational asymmetry they have relative to the investors, in our model banks exchange assets as a tool to create information asymmetry. By holding opaque portfolios banks can tilt the division of surplus in their own favor and capture rents, although

\footnotetext{
${ }^{1}$ Jiang, Levine and Lin (2016) document that an intensification in competition reduces bank opacity. Note however that in our model we take as given that banks compete to attract funds and we do not provide predictions whether decreasing the level of competition would increase opacity.
} 
this can impose net welfare losses.

The second set of results describes the implications for financial crises. Surprisingly, we find that banks choose a portfolio allocation that, at times, increases the likelihood of a financial crisis. Importantly, financial crises do not arise via the typical contagion mechanism. In fact, there is no contagion between banks in our model. Instead, financial crises arise as banks are liquidated early when investors terminate their debt contract prematurely. The mechanism that induces banks to choose a portfolio allocation which amplifies the likelihood of a financial crisis is solely due to opacity. When investors have incomplete information, the investors' liquidation decision is not precise. In particular, the investors can liquidate their bank in some states in which the bank would not default. The banks seek to exploit investors' information disadvantage to obtain a higher payoff albeit in fewer states of the world.

In the third set of results we emphasize the role of opacity by analyzing the benchmark in which investors have full information about both banks' project returns. Analyzing this case allows us to show that banks have interconnected portfolios beyond what is beneficial for diversification purposes, deliberately creating opacity for their investors. While even in the full information set-up, banks portfolio allocations can be inefficient, the implications for financial crisis are markedly different. Since investors are perfectly informed, they choose to liquidate early only if the bank cannot repay the promised debt contract. As a result, banks cannot benefit from financial crises, and they occur in equilibrium less often than it would be the case if portfolio allocation were optimal. This is in contrast with an economy with imperfect information where the probability of financial crisis can be higher in equilibrium.

Related Literature. This paper relates to several strands of literature. The most relevant studies are those on the opacity of banks, interconnections in the banking system and securitization.

It is well acknowledged that the banking system is opaque (see, e.g., Morgan, 2002; Flannery, Kwan and Nimalendran, 2013). The financial crisis of 2007-2008 emphasized the opacity of the financial system and prompted a line of research focused on the role of policies that improve transparency. Bouvard, Chaigneau, and de Motta (2015), Alvarez and Barlevy (2015), Goldstein and Leitner (2018), and Orlov, Zryumov, and Skrzypacz (2018) provide models that study the costs and benefits of disclosing bank-specific information. They show that increasing 
transparency is generally beneficial during financial crisis, but has ambiguous effects in normal economic times. A different perspective is provided by Dang, Gorton, Holmstrom and Ordonez (2017) who argue that banks need to be opaque to facilitate risk sharing. These papers take the degree of opacity in the banking system as given. In contrast, in our model the degree of opacity is endogenously determined by banks' portfolio choices. While we show that banks are indeed opaque in equilibrium, opacity is usually associated with welfare losses.

Recently, a few papers have explored the issue of endogenous information production in the context of financial markets. In Glode, Opp and Zhang (2018) and in Asriyan, Foarta and Vanasco (2018) agents who choose how much information to disclose forego informational rents to ensure that trade does not break down. Azarmsa and Cong (2018) explore how competition between financiers affects the incentives of an entrepreneur to produce information. These papers do not address the role of endogenous opacity in banking crises, which is one of our main interests of analysis.

In our model, opacity is a result of interconnections between banks. The literature on bank linkages is rapidly growing, not surprisingly given the prominence of interconnectedness in the US financial system and its role during the last financial crisis. The papers that are more related to ours study interconnections that arise when banks have overlapping portfolio exposures. These papers are focused on understanding whether common exposures between banks' portfolios can amplify systemic risk. For instance, Shaffer (1994), Wagner (2010) and Ibragimov, Jaffee and Walden (2010) show that diversification is beneficial for each bank individually, but it can lead to greater systemic risk as banks' investments become more similar. Adrian and Brunnermeir (2016) propose a measure of systemic risk based on co-movement of financial institutions' assets and liabilities. However, with the exception of Allen, Babus and Carletti (2012), information is not central to the mechanism explored in these papers. Even in Allen et al. (2012) banks do not choose explicitly how opaque they want to be, even though linkages between them are endogenous. In addition, in that model banks have market power relative to investors. Instead, we assume that investors do not just break even, but are able to extract rents from the banks.

Interconnections between banks in our set-up arise as banks exchange a fraction of their portfolio. While this can be interpreted as banks securitizing assets, our mechanism has differences with the one which securitization relies on. In particular, when securitizing, the originator 
signals the quality of the project by retaining a fraction on its balance-sheet (DeMarzo, 2004; Duffie, 2008; Chemla and Hennessy, 2014; Vanasco, 2017). This channel is absent from our model. Instead, our paper highlights an important adverse consequence of securitization generally overlooked in the literature: by securitizing assets, banks deliberately produce opaque portfolios to capture informational rents, although this can increase the probability of banking crises.

The rest of the paper is organized as follows. In section 2 we introduce the model set-up, and we explain how we solve for equilibrium, as well as for the optimal portfolio allocation. Our main results are presented in Section 3. In Section 4 we introduce the full information benchmark to highlight the role of opacity. Section 5 concludes.

\section{The Model}

\subsection{The Model Set-Up}

Consider a three-period $(t=0,1,2)$ economy with two risk-neutral banks, denoted by $i=1,2$, and two risk-neutral investors, denoted by $I=1,2$. At date 0 , each bank $i$ has access to a risky investment project that returns $R_{i}$ at date 2 . For each bank $i$, the return $R_{i}$ is an independent draw from a uniform probability distribution $G(\cdot)$, with support $[0,1]$. Each investment project represents loans to a continuum of firms that have perfectly correlated risks. Each investor $I$ is endowed with funds. To invest in the project, bank $i$ raises funds from investor $I$.

Banks choose whether to exchange a fraction of their project. In particular, a bank $i$, chosen at random, proposes to exchange a fraction $(1-\phi)$ of her project for a fraction $(1-\phi)$ of bank $j$ 's project. Bank $j$ can accept or reject. If she rejects, no exchange takes place. If she accepts, bank $i$ 's portfolio is

$$
V_{i}(\phi)=\phi R_{i}+(1-\phi) R_{j}
$$

while bank $j$ 's portfolio is

$$
V_{j}(\phi)=\phi R_{j}+(1-\phi) R_{i}
$$

In exchange for borrowing funds from the investor, each bank issues a debt contract with face value $D$ that matures at date $2 .^{2}$ The face value of debt is set to maximize the investor's

\footnotetext{
${ }^{2}$ Banks are symmetric, thus debt contract each issues is the same $\left(D_{i}=D_{j}=D\right)$.
} 
expected surplus, given that he lends all his funds.

At date 1 , a signal perfectly reveals the return $R_{i}$ of the project of each bank $i$. Each investor $I$ observes the return $R_{i}$, but not $R_{j}$. Each bank $i$ observes both returns $R_{i}$ and $R_{j}$ whenever $\phi \in(0,1)$. It follows that from the perspective of an investor, $\phi$ captures the degree of transparency of a bank's portfolio. When $\phi$ is high, then investor I's signal is more informative about the final realization of bank $i$ 's portfolio. Conversely, the lower $\phi$ is, the more opaque the bank's portfolio is, and thus the less informative investor's signal is.

After observing $R_{i}$, investor $I$ decides whether to liquidate his investment, or continue and wait to receive $D$ at date 2 . We represent investor $I$ 's decision through a function

$$
s_{I}\left(R_{i}\right)=\left\{\begin{array}{ll}
1 & \text { if investor } I \text { continues bank } i \\
0 & \text { if investor } I \text { liquidates bank } i
\end{array} .\right.
$$

If an investor $I$ chooses to liquidate, he receives an early redemption value $0<r<E\left(R_{i}\right)$. Liquidation of bank $i$ does not affect the state of the project of bank $j$.

If an investor $I$ chooses to continue, then he receives $D$ at date 2 , if $V_{i} \geq D$ and zero otherwise. The bank $i$ is the residual claimant and receives at date 2

$$
\max \left\{V_{i}-D, 0\right\}
$$

The underlying assumption is that if return of the portfolio $V_{i}$ is not sufficient to repay the debt to the investor, the bank is insolvent and all the proceeds of portfolio are foregone in bankruptcy.

In this set-up we use the following equilibrium concept.

Definition 1 A symmetric equilibrium is given by a portfolio allocation $\left(\phi^{*}, 1-\phi^{*}\right)$, a face value of debt $D^{*}$, and continuation decision $s_{I}^{*}\left(R_{i}\right)$ of each investor I given signal $R_{i}$ such that

1. the continuation decision maximizes each investor I's expected payoff at date 1

$$
\max _{s_{I}}\left\{s_{I}\left(R_{i}\right) \cdot D \cdot \operatorname{Pr}\left(D \leq V_{i}(\phi) \mid R_{i}\right)+\left(1-s_{I}\left(R_{i}\right)\right) \cdot r\right\}
$$


2. the face value of debt maximizes each investor I's expected payoff at date 0

$$
\max _{D} \mathbb{E}_{R_{i}}\left\{s_{I}\left(R_{i}\right) \cdot D \cdot \operatorname{Pr}\left(D \leq V_{i}(\phi) \mid R_{i}\right)+\left(1-s_{I}\left(R_{i}\right)\right) \cdot r\right\}
$$

3. the portfolio allocation maximizes each bank $i$ 's expected payoff at date 0

$$
\max _{\phi} \mathbb{E}_{R_{i}, R_{j}}\left\{s_{I}\left(R_{i}\right) \cdot \max \left[\left(V_{i}(\phi)-D\right), 0\right]\right\}
$$

Implicitly, the optimal continuation decision is a function of the face value of debt as well as the fraction of the project the bank retains in its portfolio, i.e. $s_{I}^{*}\left(R_{i}\right)=s_{I}^{*}\left(R_{i} ; D, \phi\right)$. Similarly, the face value of debt is a function of the fraction of the project the bank retains in its portfolio, i.e. $D^{*}=D^{*}(\phi)$. In the exposition below, we take these dependencies as implicit so not to burden excessively the notation.

\subsection{Equilibrium Derivations}

We solve for the equilibrium in two steps. First we solve for the investors' optimal liquidation decision, and the optimal face value of debt, as described by condition (1) and (2) in Definition 1 , given that each bank retains a fraction, $\phi$, of her project. Second, we solve for the optimal portfolio allocation, $\phi$, taking into account that each bank understands that investors behave optimally. We start with the case $\phi \in(0,1)$. We analyze the case of $\phi=0$ and $\phi=1$ separately, to highlight when banks have perfectly opaque or perfectly transparent portfolios.

In the first step, we start by analyzing investors' continuation decision. For each portfolio allocation, $\phi \in(0,1)$, and each face value of debt, $D$, set at date 0 , the optimal continuation decision at date 1 must satisfy

$$
s_{I}^{*}\left(R_{i}\right)=\arg \max \left\{s_{I}\left(R_{i}\right) \cdot D \cdot \operatorname{Pr}\left(D \leq V_{i}(\phi) \mid R_{i}\right)+\left(1-s_{I}\left(R_{i}\right)\right) \cdot r\right\} .
$$

Thus, it is optimal for the investor $I$ to continue funding bank $i$ if $D \cdot \operatorname{Pr}\left(D \leq V_{i}(\phi) \mid R_{i}\right)$, the amount he expects to receive at date 2 , given that his signal is $R_{i}$, is larger than the reservation value $r$, he obtains when he liquidates the bank at date 1. Investor's decision to continue funding the bank depends thus on how high the face value of debt is, as well as how 
high the probability that the investor gets repaid. Indeed, if realization of $R_{i}$ is sufficiently high that $D<\phi R_{i}$, then the investor gets repaid $D$ with certainty. However, if $D \geq \phi R_{i}$, then the investor gets repaid $D$ only if $R_{j} \geq \frac{D-\phi R_{i}}{1-\phi}$, which occurs with probability $\left(1-G\left(\frac{D-\phi R_{i}}{1-\phi}\right)\right)$. Otherwise, the bank goes into default at date 2, and the depositor gets 0 .

This implies that investor $I$ finds it optimal to continue funding bank $i$ when

$$
\operatorname{Pr}\left(R_{j} \geq \max \left\{\frac{D-\phi R_{i}}{1-\phi}, 0\right\} \mid R_{i}\right) \geq \frac{r}{D}
$$

or when his signal is sufficiently large. In particular, investor's optimal continuation decision can be characterized by a threshold strategy as follows

$$
s_{I}^{*}\left(R_{i}\right)=\left\{\begin{array}{ll}
1 & \text { if } R_{i} \geq R^{*} \\
0 & \text { if } R_{i}<R^{*}
\end{array},\right.
$$

where

$$
R^{*}=\max \left\{\min \left\{1, \frac{D}{\phi}-\frac{1-\phi}{\phi} G^{-1}\left(1-\frac{r}{D}\right)\right\}, 0\right\} .
$$

Thus, $R^{*}$ represents the probability that an investor liquidates his bank at date 1 . Equation (3) reveals that investor's continuation decision depends non-linearly on $D$. Clearly, if the face value of debt is too low, the investor liquidates the bank, as he is better off cashing in the liquidation value $r$. However, the investor is also more likely to liquidate when the face value of debt is too high. In fact, the probability that investor liquidates the bank increases in the level of debt, when $D$ is sufficiently high. This is because the probability an investor associates to being repaid decreases faster than his relative opportunity cost of continuing the bank, $r / D$. These forces play an important role in determining the optimal face value of debt, which we discuss next.

We turn to derive the optimal face value of debt taking as given a portfolio allocation $\phi$, and taking into account that investors make the optimal continuation decision at date 1 . Investor I's expected payoff is given by

$$
W_{I}=\mathbb{E}_{R_{i}}\left\{s_{I}^{*}\left(R_{i}\right) \cdot D \cdot \operatorname{Pr}\left(D \leq V_{i}(\phi) \mid R_{i}\right)+\left(1-s_{I}^{*}\left(R_{i}\right)\right) \cdot r\right\}
$$




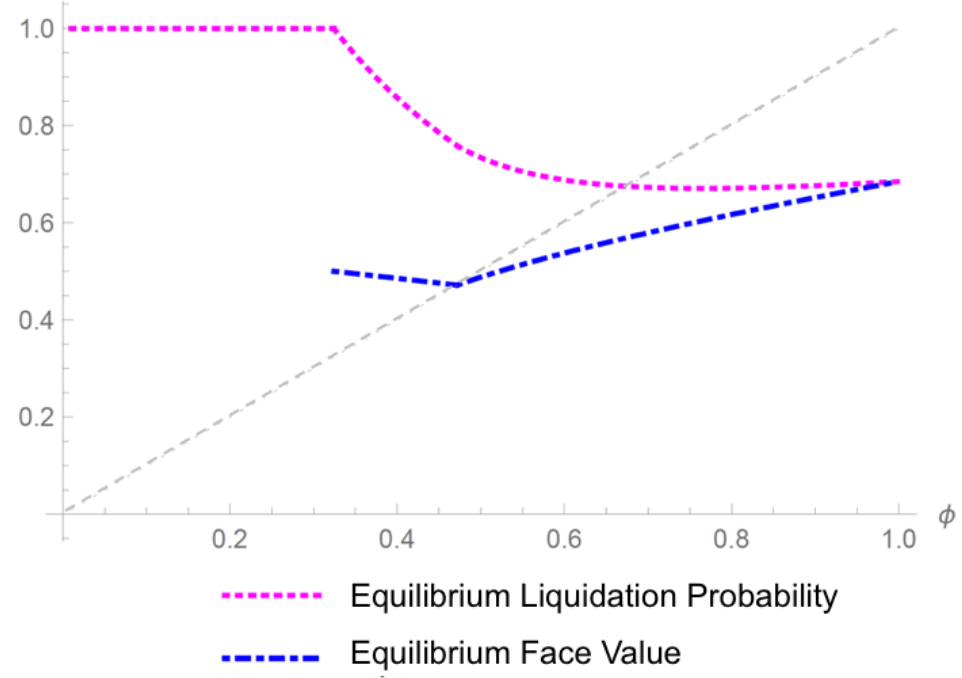

Figure 1: The figure illustrates the equilibrium liquidation probability, $R^{*}$, and the optimal face value of debt, $D^{*}$, as a function of the degree of transparency of a bank's portfolio, $\phi$, for $r=0.37$. The dashed line represent the 45 -degree degree line.

or

$$
W_{I}=D \cdot \mathbb{E}_{R_{i}}\left(\operatorname{Pr}\left(R_{j} \geq \frac{D^{*}-\phi R_{i}}{1-\phi}\right) \mid R_{i} \geq R^{*}\right) \operatorname{Pr}\left(R_{i} \geq R^{*}\right)+r \cdot \operatorname{Pr}\left(R_{i}<R^{*}\right)
$$

The first term on the right hand side of (4) and (5) represents investor I's expected payoff provided he continues funding bank $i$. The second term on the right hand side of (4) and (5) represents investor's expected payoff provided he liquidates the bank at date 1.

Thus, making use of (2), the face value of debt satisfies

$$
D^{*}=\arg \max \left\{D\left[\int_{R^{*}}^{1}\left(1-G\left(\frac{D-\phi R_{i}}{1-\phi}\right)\right) d G\left(R_{i}\right)\right]+r G\left(R^{*}\right)\right\}
$$

Figure 1 illustrates the solution to (6) as well the corresponding continuation decision of investor $I$, as a function of the degree of transparency of his bank $i$, for a given reservation value $r$. The key observation is that as $\phi$ increases, investors' information improves. This leads to a more precise liquidation decision, and the liquidation threshold $R^{*}$ and optimal face value $D^{*}$ converge to each other. In fact, when investors are fully informed $(\phi=1)$, the liquidation 


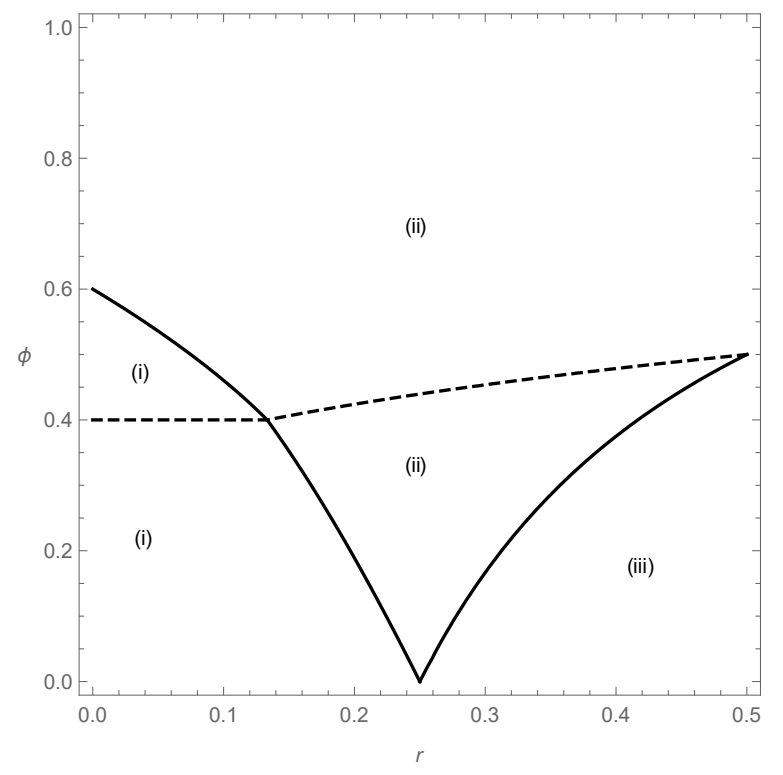

Figure 2: The figure illustrates how the liquidation probability $R$ and the face value of debt $D^{*}$ depend on the investor's reservation value, $r$, and of the fraction, $\phi$. In region (i), $R=0$. In region (ii), $R \in(0,1)$. In region (iii), $R=1$. The dashed lines in regions (i) and (ii) represent the thresholds above which the equilibrium face value of debt $D^{*} \leq \phi$, and below which $D^{*}>\phi$.

threshold is $R^{*}=D^{*}$. In the other extreme, if the degree of transparency of bank $i$ 's portfolio is too low, then there exists no face value of debt for which the investors are willing to continue the bank, and $R^{*}=1$.

A general characterization of the investor optimal decision, i.e. the probability $R^{*}$ that a bank is liquidated and the face value of debt $D^{*}$, as a function of the investor's reservation value, $r$, and of the fraction that the bank retains of her own project, $\phi$, is provided in Lemma A.1 in the Appendix. Figure 2 illustrates the results stated in the Lemma. When $r$ is low and $\phi$ is not too high, as in Region (i) in Figure 2, the repayment an investor expects to receive from his bank at date 2 is sufficiently high that he always continues the bank. As $r$ increases, the investor continues the bank with probability 1 only if he does not have sufficiently precise information about the bank's portfolio, or when $\phi$ is lower. Indeed, the threshold $\phi_{\text {i-ii }}(r)$ that separates Region (i) and Region (ii) is decreasing $r$. This is because when the investor is relatively uninformed the face value of debt can be set to compensate him in expectation for not liquidating early, provided $r$ is small. In other words, opacity makes investors passive 
when $r$ is low. However, as the investors' reservation value, $r$, increases and banks portfolios remain relatively opaque, or $\phi$ is not too high, as in Region (iii) in Figure 2, investors no longer tolerate opacity. Thus, in Region (iii), there exists no level of the face value of debt for which an investor is willing to continue the bank at date 1. Thus opacity makes investors aggressive when $r$ is high. This is reflected in the threshold $\phi_{\mathrm{ii}-\mathrm{iii}}(r)$ that separates Region (ii) and Region (iii) which is increasing $r$.

When $\phi$ is high and the banks' portfolios are relatively transparent, an investor continues his bank with probability $R^{*} \in(0,1)$ for a large range of his reservation value, $r$, as shown in Region (ii) in Figure 2. This also holds for lower levels of $\phi$, as long as $r$ is not too high.

We distinguish two main cases when $R^{*}<1$ and the investor is willing to continue his bank with positive probability: $D^{*} \leq \phi$ and $D^{*}>\phi$. When $D^{*} \leq \phi$, then there exists values of $R_{i}$ such that bank $i$ can repay the investor from the realization of its own project. Thus, the signal that investor $I$ receives at date 1 can be sufficiently informative about whether he will be repaid at date 2 . When $D^{*}>\phi$, it is necessary that bank $j$ 's project has a sufficiently good realization for bank $i$ to be able to repay the debt to the investor at date 2 . In this case, the signal that investor $I$ receives at date 1 is less informative, as the investor is uncertain about whether he will be repaid or not even if $R_{i}$ is high. The dashed lines in Region (i) and Region (ii) in Figure 2 represent the thresholds above which the equilibrium face value of debt $D^{*} \leq \phi$, and below which $D^{*}>\phi$.

In the second step, we analyze banks' decision about what fraction, $\phi$, of their loans to retain in their portfolio. When banks choose their optimal portfolio, they take into account that the investors make optimal decisions. That is, a bank $i$ understands that each fraction $(1-\phi)$ of loans it exchanges with the other bank induces a continuation decision $s_{I}$, and a face value of debt $D$. Thus for each $\phi$, and $s_{I}^{*}$ and $D^{*}$ associated with that $\phi$, the bank $i$ 's expected payoff is

$$
W_{i}=\mathbb{E}_{R_{i}}\left\{\mathbb{E}_{R_{j}}\left\{\max \left[\left(\phi R_{i}+(1-\phi) R_{j}-D^{*}\right), 0\right]\right\} \cdot s_{I}^{*}\left(R_{i}\right)\right\}
$$

or

$$
W_{i}=\mathbb{E}_{R_{i}}\left\{\mathbb{E}_{R_{j}}\left\{\left(\phi R_{i}+(1-\phi) R_{j}-D^{*}\right) \mid R_{j} \geq \frac{D^{*}-\phi R_{i}}{(1-\phi)}\right\} \mid R_{i} \geq R^{*}\right\} \operatorname{Pr}\left(R_{i} \geq R^{*}\right) .
$$

Isolating $D^{*}$, and substituting the investor's payoff, we can write bank $i$ 's expected payoff in 
(5) as

$W_{i}=\mathbb{E}_{R_{i}}\left\{\phi R_{i}+(1-\phi) \mathbb{E}_{R_{j}}\left\{R_{j} \mid R_{j} \geq \frac{D^{*}-\phi R_{i}}{(1-\phi)}\right\} \mid R_{i} \geq R^{*}\right\} \operatorname{Pr}\left(R_{i} \geq R^{*}\right)+r \cdot \operatorname{Pr}\left(R_{i} \leq R^{*}\right)-W_{I}$.

The sum of first two terms in (7) represents the total surplus that is expected to be realized when investor $I$ finances bank $i$. The last term is simply investor $I$ 's payoff. Thus, in equilibrium, each bank $i$ chooses the fraction, $\phi$, of her project to retain in her portfolio such that the expected marginal total surplus equals the marginal investor's payoff. To the extent that these two term are not proportional, a wedge arises between the planner and the bank.

The optimal degree of transparency, $\phi^{*}$ solves

$$
\phi^{*}=\arg \max \left\{\int_{R^{*} \max \left\{\frac{D^{*}-\phi R_{i}}{1-\phi}, 0\right\}}^{1} \phi R_{i}+(1-\phi) R_{j}-D^{*} d G\left(R_{j}\right) d G\left(R_{i}\right)\right\} .
$$

The bank's objective is to choose a portfolio allocation $\left(\phi^{*}, 1-\phi^{*}\right)$ that would result in the lowest face value of debt, $D$, for which the investor often continues to fund the bank. In making this choice, the bank weighs two forces: the ex-post probability of default at date 2 and the probability of liquidation at date 1. Exchanging a fraction of its loans with the other bank diversifies bank $i$ 's portfolio. At the same time, it creates opacity about her portfolio return, as investor $I$ has information only about bank $i$ 's project. Through diversification, the bank can decrease the ex-post probability of default at date 2. However, increasing the opacity of the portfolio has mixed effects on investors' decision to liquidate the bank. When possible, the bank chooses a degree of transparency $\phi$ to decrease both the ex-post probability of default at date 2 and the probability of liquidation at date 1 . This is the case when $D^{*}>\phi$ in Region (ii) in Figure 2. However, there are parameters for which the probability that the investor liquidates the bank is not monotonic in $\phi$, as it is the case when $D^{*} \leq \phi$ in Region (ii) in Figure 2. Then, the bank faces a trade-off between the marginal change she induces in the expost probability of default relative to the marginal change she induces in the probability that the investors liquidate the bank. In this case, the optimal choice of the degree of transparency has interesting implications for welfare and financial crises, as we discuss in Section 3. 
We now characterize the two extreme bank choices of opacity, $\phi=0,1$. The case of $\phi=1$, when each bank retains all of her project and the investors are perfectly informed, is straightforward. Investor $I$ continues to fund bank $i$ when the signal he receives $R_{i}$ is larger than the face value of debt $D$, i.e. when he is certain that the bank does not default at date 2. In other words, his continuation strategy is given by $(2)$ where $R^{*}=D$. At the same time, the face value of debt must solve the following maximization problem

$$
\max _{D}\left\{D\left[\int_{R^{*}}^{1} 1 d G\left(R_{i}\right)\right]+r G\left(R^{*}\right)\right\},
$$

and the first order condition implies that

$$
D^{*}(1)=\frac{1+r}{2}
$$

Thus, the investor continues the bank with probability $\frac{1-r}{2}$.

The case of $\phi=0$, when each bank swaps the entire project with the other bank, is similarly straightforward. The signal that the investors receive at date 1 is not informative about the return of their bank portfolio. Thus, an investor continues the debt contract with the bank provided the amount he expects to be repaid at date $2, D \cdot \operatorname{Pr}\left(D \leq V_{i}(0)\right)$, exceeds the reservation value he obtains when he liquidates the bank at date $1, r$. Then, the face value of debt must solve the following maximization problem

$$
\max _{D}\left\{D\left[\int_{D}^{1} d G\left(R_{j}\right)\right]\right\}
$$

and the first order condition implies that

$$
D^{*}(0)=\frac{1}{2}
$$

Thus, if $r<\frac{1}{4}$ the investor continues the bank with probability 1 and receives $D^{*}(0)$ at date 2 with probability $\frac{1}{2}$. Otherwise, if $r \geq \frac{1}{4}$ there exists no face value of debt that can induce the investor to continue the bank. 


\subsection{Constrained Planner and Welfare}

We start by introducing the social planner optimization problem. Our definition of welfare aggregates banks' and investors' expected payoffs as of date 0, and can be written as

$$
W^{S}=2 \times \mathbb{E}_{R_{i}}\left\{\left[\phi R_{i} \operatorname{Pr}\left(R_{j} \geq \frac{D^{*}-\phi R_{i}}{1-\phi}\right)+(1-\phi) \mathbb{E}\left(R_{j} \mid R_{j} \geq \frac{D^{*}-\phi R_{i}}{1-\phi}\right)\right] \cdot s_{I}^{*}\left(R_{i}\right)+r \cdot\left(1-s_{I}^{*}\left(R_{i}\right)\right)\right\} .
$$

The social planner chooses a fraction of the project, $\phi^{S}$, that each bank retains such that

$$
\phi^{S}=\arg \max \int_{R^{*}}^{1}\left[\phi R_{i}\left(1-G\left(\max \left\{\frac{D^{*}-\phi R_{i}}{1-\phi}, 0\right\}\right)\right)+(1-\phi) \int_{\max \left\{\frac{D^{*}-\phi R_{i}}{1-\phi}, 0\right\}}^{1} R_{j} d G\left(R_{j}\right)\right] d G\left(R_{i}\right)+r G\left(R^{*}\right)
$$

given that the face value of debt satisfies (6) and investors take optimal continuation decisions that satisfy (1).

The social planner's and the banks' incentives are partially aligned, as both benefit when investors continue to fund the bank and when default is avoided. However, two wedges may arise between the social planner and the banks.

The first wedge arises because banks do not internalize that in case of early liquidation, investors nevertheless obtain their reservation value, $r$. In contrast, for the social planner, the early liquidation payoff represents nevertheless a welfare gain even when a bank defaults. Moreover, as $r$ increases, investors obtain a good payoff if they liquidate early. Thus, even if banks choose a portfolio allocation that decreases the probability of liquidation, it may be the case that the expected welfare gain from continuation increases by less. This force is most clearly identified by allowing investors to have full information about both banks' projects, a set-up which we characterize formally in the Section 4 .

Even when the first wedge is less relevant, a second wedge arises as the social planner and the banks associate a different relative importance to being continued vs. defaulting. That is, the trade-off between the ex-post probability of default and the probability that the investors liquidate the bank resolves differently for the social planner. This is because, each bank, as a residual claimant on the return of her portfolio, prefers to receive a higher payoff albeit in fewer states of the world. Therefore, it may be optimal for the bank to chose a portfolio 
allocation under which investor receive a lower face value of debt, even if this implies that investors are more likely to liquidate. In contrast, from the perspective of a social planner, the face value of debt is a transfer from the bank to the investor. Provided that investors are not too highly compensated for liquidating early, the social planner's objective is to chose a portfolio allocation $\left(\phi^{S}, 1-\phi^{S}\right)$ for each bank that yields a face value of debt, $D^{S}$, such that the surplus is realized in as many states of the world as possible. While the planner may also be concerned that the face value of debt is be too high, this is because the bank can become insolvent and default at date 2. This trade-off is present only when investors have incomplete information about their banks' portfolio and has significant implications for the probability of financial crises.

It is instructive to consider the implications of our model if the only possible choices for the bank and the constrained planner were full opacity $(\phi=0)$ and full transparency $(\phi=1)$. Direct comparison of these two extreme cases reveal three key outcomes. First, from the perspective of the planner, it is always better to have fully transparent banks. In the absence of diversification benefits, full opacity only makes the investors' liquidation decision less precise, which leads to surplus being destroyed inefficiently. Thus, welfare under full transparency is higher than under full opacity.

Second, the banks prefer to be fully opaque if $r<\frac{1}{4}$, while they choose a fully transparent portfolio if $r \geq \frac{1}{4}$. When $r<\frac{1}{4}$, opacity makes investors passive, and they choose to continue their bank with probability 1 . Banks favor this outcome, since they need to pay a lower face value of debt than when they have perfectly transparent portfolios. When $r \geq \frac{1}{4}$, opacity makes investors aggressive and they will always liquidate the bank at date 1. A bank can persuade the investor to continue the contract with positive probability if only and if she holds a perfectly transparent portfolio. In this case, the investor continues his banks with probability $\frac{1-r}{4}$. Therefore, the bank is too opaque relative to the constraint efficient allocation if and only if $r<\frac{1}{4}$. We show in the next section how investors' and banks' incentives adjust to intermediate levels of opacity.

The third key implication is that the probability of early bank li quidation, or of a financial crisis, is always weakly lower in equilibrium compared to when the banks choose fully transparent portfolios, as in the constraint efficient outcome. In other words, banks always prefer to avoid early liquidation. However, as we argue in the next section, narrowing banks' choice 
to be either fully opaque or fully transparent misses an important consequence of opacity, namely bank strategic exposure to financial crises. We show that such behavior only emerges if banks can fine-tune how much information they provide to investors by choosing portfolios with intermediate level of opacity, $\phi \in(0,1)$.

\section{Equilibrium and Optimal Opacity}

In this section we formally introduce our results. The first set of result characterizes the equilibrium portfolio allocation, and contrasts it with the portfolio allocation that maximizes welfare. The second set of results addresses the implications of the equilibrium portfolio allocation for financial crises. We say a financial crisis occurs when a bank is liquidated at date 1 .

We start by characterizing banks' equilibrium portfolio allocation in the following proposition.

Proposition 1 There exists $r_{h}$ such that for any $r<r_{h}$, banks hold in equilibrium interdependent and opaque portfolios, or $\phi^{*} \in(0,1)$. If $r \geq r_{h}$, banks have independent and perfectly transparent portfolios, or $\phi^{*}=1$.

When investors' payoff, $r$, from early liquidation is not too high, neither full transparency, nor full opacity are desirable for the banks. The intuition is as follows. When banks exchange projects there are two effects. First, each bank's portfolio is more diversified, which reduces the likelihood of default at date 2. Second, each bank's portfolio is more opaque. As we have discussed above, when $\phi=1$ and the investor has perfect information, he liquidates the bank if and only if the bank defaults at date 2. When the bank's portfolio is opaque, the investor's liquidation decision is less precise. That is, the investor liquidates the bank even in some states in which the bank would not default and, conversely, the investor continues the bank even in some states in which the bank would default. Both diversification and opacity act as forces to lower the face value of debt, $D^{*}$, that maximizes the investors expected surplus, as long as the investor's reservation value is not too high. This favors the bank who then seeks to acquire a fraction of the other bank's project. However, if banks fully swap their projects, any gains from diversification are foregone. Moreover, when $\phi=0$, the investor is completely uninformed so he needs to be compensated more in expectation, in order to retain his investment in the bank. 
Thus, the optimal portfolio allocation is interior. In the next section we also show that the portfolio banks hold in equilibrium is under-diversified, a direct consequence of banks' decision to create opacity.

When the reservation value of the investor is too attractive, he will continue to fund the bank only when he is certain that he will receive a sufficiently high face value of debt, conditional on his information at date 1 . In this case, the bank must retain all of his project, as investor does not tolerate any degree of uncertainty about the portfolio return.

A direct implication of Proposition 1 is that banks incur a negative premium for holding opaque and interconnected portfolios, as long as $r \leq r_{h}$. This premium is defined as the difference between a bank's payoff when she holds a perfectly transparent portfolio $(\phi=1)$ and the payoff she obtains in equilibrium, conditional on being continued. The next proposition shows that the gain banks obtain from opacity is at the expense of the investors.

Proposition 2 There exists $r_{l}$ such that for any $r>r_{l}$, welfare is maximized when banks have independent and perfectly transparent portfolios, or $\phi^{S}=1$. If $r<r_{l}$, welfare is maximized when banks have interdependent and opaque portfolios, and $\phi^{S}=\phi^{*}<1$.

Despite the diversification benefits that arise when banks exchange projects, the social planner finds it optimal that banks have independent portfolios if $r$ is not too low. There are two reasons for this. First, even if the probability of liquidation may be higher when banks have independent portfolio than when they have diversified portfolios, the welfare gain that investors obtain from their reservation value, $r$, may compensate for the welfare loss when the bank is liquidated early. Second, investors have perfect information about their bank portfolio return when $\phi=1$. As we have seen in the previous section, when $\phi=1$, the face value of debt $D^{*}=R^{*}$. Thus investor $I$ continues to fund bank $i$ only when he is certain he will receive $D$, given he knows that the return of $i$ 's project is $R_{i}$ at date 1 . In other words, the investor liquidates the bank only when the bank would otherwise default at date 2 . In this case, no surplus is destroyed inefficiently. In contrast, when $\phi<1$ there can be a welfare loss because when bank $i$ is liquidated the $(1-\phi)$ share of project originated by bank $j$ that $i$ owns is liquidated as well, even though it could yield a high return.

A direct consequence of Proposition 2 is that equilibrium portfolio allocations decrease welfare for intermediate values of the investors' reservation value, $r$. In Figure 5 we plot the 
difference between the payoff that a bank obtains in equilibrium and the payoff that a bank obtains when she holds the efficient portfolio as a function of $r$. The figure illustrates that indeed banks gain from opacity, instead of incurring a cost, at the expense of the investors.

Formally, we show that $r_{l}<r_{h}$, such that the divergence between the social planner and the banks arises when $r \in\left(r_{l}, r_{h}\right)$. The next proposition introduces this result and identifies the main sources of the inefficiency.

Proposition 3 For any $r \in\left(r_{l}, r_{h}\right)$ banks' portfolios are inefficiently opaque. Moreover, there exists $r_{m} \in\left(r_{l}, r_{h}\right)$ such that

1. If $r_{l}<r<r_{m}$, the investors continue their bank too frequently, or $R^{*}\left(\phi^{*}\right)<R^{*}(1)$.

2. If $r_{m}<r<r_{h}$, the investors liquidate their bank too frequently, or $R^{*}\left(\phi^{*}\right)>R^{*}(1)$.

Proposition 3 essentially characterizes the probability of financial crises as a function of the banks' portfolio choices. Recall that we consider a financial crisis occurs when the bank is liquidated at date 1 . While financial crises may be efficient conditional on banks' choices, welfare losses arise nevertheless either because crises occur too frequently or too infrequently. There are two channels that explain why inefficiencies occur. First, the banks default too often at date 2 if they are not liquidated early. That is, there are cases when investors choose to forego $r$ and not liquidate the bank, but the bank defaults at date 2 and investors receive zero. This is shown in the first part of Proposition 3. Second, banks are liquidated too often at date 1: there are cases when investors choose to liquidate the bank and only receive $r$. However, if the bank were not liquidated, it would be solvent and pay out $D>r$ to investors at $t=2$. This is shown in the second part of Proposition 3.

The intuition is as follows. Given equilibrium $D^{*}$ and $\phi^{*}$ set at $t=0$, investor $I$ has an ex-ante expectation of his payoff, in case he does not liquidate the bank. At $t=1$, when investor $I$ observes signal $R_{i}$, he updates the expectation of his payoff given his signal. When $r \in\left(r_{l}, r_{m}\right)$, banks choose relatively opaque portfolios. Thus investor $I$ 's signal is relatively uninformative. It follows that unless $R_{i}$ is very low, the investor does not revise his expected payoff significantly downward, and he chooses to continue the bank. This leads the investor to continue funding the bank too often relative to the case when banks hold the socially optimal 


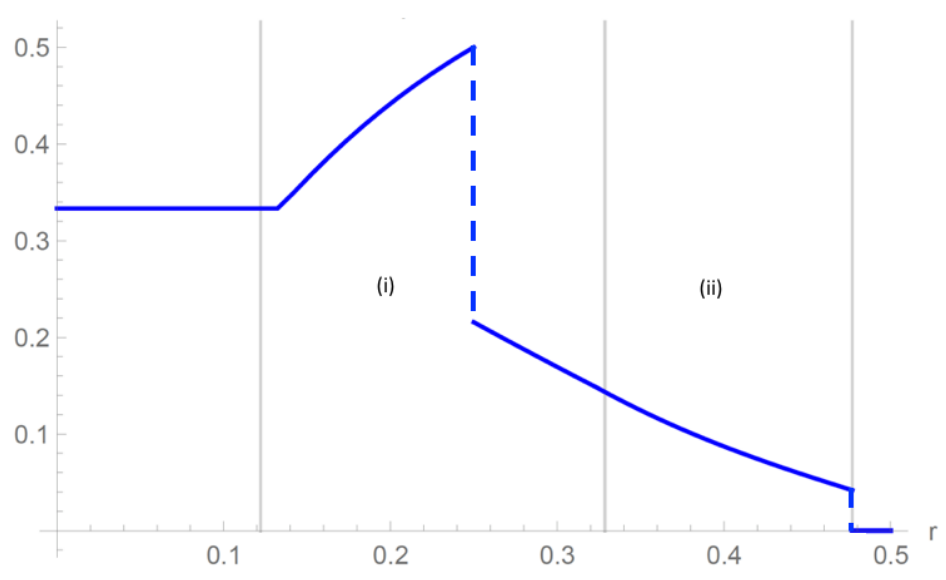

— Equilibrium Expost Default Probability Conditional on Continuation

Figure 3: The figure illustrates the probability, $\operatorname{Pr}\left(D>V_{i} \mid R_{i}>R^{*}\right)$, that a bank defaults at date 2 , when at date 1 investors have learned the signal and decided to continue funding the bank, given the equilibrium degree of transparency, as well as the optimal degree of transparency. We distinguish two regions: Region (i), when $r \in\left(r_{l}, r_{m}\right)$ and Region (ii), when $r \in\left(r_{m}, r_{h}\right)$.

portfolio. Since a large part of bank $i$ portfolio depends on realization of $R_{j}$, ex-post the banks default frequently, as illustrated in Figure 3, Region (i).

When $r \in\left(r_{m}, r_{h}\right)$, the banks choose relatively transparent portfolios, since investors' reservation value, $r$, is high. As investor's interim signal at $t=1$ is informative, he substantially updates his expectation about the payoff he obtains in case he does not liquidate the bank. Thus even for an intermediate realization of the signal, concern that his bank will default at date 2 prompts the investor to liquidate the bank. This leads to too frequent liquidation relative to the case when the bank holds the socially optimal portfolio. It also implies that the investor only continues to fund the bank when his signal is relatively high, which leads to a healthy bank balance sheet since $R_{i}$ is a significant share of bank i's portfolio. As a result, conditional on continuation, the bank rarely defaults at $t=2$, as illustrated in Figure 3, Region (ii). The bank favors this outcome as well since its payoff conditional on being continued is sufficiently high to compensate for the fact that she is liquidated more frequently.

Note that the liquidation probability is monotonically increasing in $r$, but the degree of opacity is non-monotonic, as illustrated in Figure 4. The first observation is intuitive: the 
liquidation value $r$ represents investors outside option, and a higher outside option increases the probability of liquidating the bank. By the same logic, one would expect the equilibrium opacity to be monotonically decreasing in $r$. Indeed, higher bank transparency can increase investor's likelihood that he receives his date 2 payoff, attenuate the increase in probability of liquidation, and improve bank's payoff.

Although this logic holds once $r$ is sufficiently high, it is not globally true. In fact for low levels of liquidation value, opacity is weakly increasing (transparency, $\phi$, weakly decreasing) in $r$. The reason is that when $r$ is not too high, banks recognize that by giving their investors a sufficiently risky payoff with a high upside, as represented by a high face value of debt, they can remove the liquidation threat all together. It follows that to induce a sufficiently high face value of debt, equilibrium opacity increases in $r$ until it peaks at $r=\frac{1}{2}$, while $R^{*}$ is zero, i.e. the bank is never liquidated. Above this threshold the investor's outside option is sufficiently high that he sometimes liquidates the bank, regardless of the degree of opacity, as we explained above.

It is important to observe that the second part of Proposition 3 implies that the probability of a financial crisis is higher when banks have correlated portfolios than when they have independent portfolios. Counterintuitively, in our model banks choose a portfolio allocation that increases the likelihood of a banking crisis. At the same time, the face value of debt that compensates investors is lower than the one that prevails when the banks are less exposed to crises, as is the case when $\phi=1$. A banking crisis can occur even when there is a positive probability that the bank's portfolio yields a positive return if continued. This suggests that government interventions and bailout policies can only increase the probability of banking crises by further distorting banks' incentives, and thus are inefficient.

Furthermore, the model also provides an interesting set-up to think about the timing of bailouts. Specifically, in the context of our model, the government can intervene at two distinct times. First, at $t=1$ when investors receive a low signal and intend to liquidate the banks, the government can intervene and allow the banks to continue. Second, at $t=2$, if a bank does not have enough resources, the government can intervene and repay the face value of debt to investors. Neither intervention involves a transfer of government resources to bank equity holders, but the two bailout policies have very different implications for the equilibrium degree of opacity, as well as for the banks' and investors' payoff. Thus, by explicitly modeling the 
strategic interactions between banks and investors, our framework allows for comparing the equilibrium implications of government intervention when banks are illiquid versus when they are insolvent.

Another interpretation of Proposition 3 is in terms of investors' use of their information. When banks have independent portfolios, investors are relatively information insensitive, in the sense that they only liquidate the bank if they anticipate a low return of their bank's project. Once the bank chooses to exchange projects, investors become more information sensitive, by taking actions based on the (partial) information that they receive about their bank portfolio.

While $r$ in our set-up is an exogenous parameter, it can be thought as capturing in a reduced form liquidity in the secondary market, as most recently modeled in Dewatripont and Tirole (2018). An improvement in the secondary market can be then equivalent to increasing $r$, which effectively acts as an outside option for investors. Then, an implication of our model is that more liquidity in the secondary market has an adverse effect: it provides incentives for investors to liquidate the bank early as they can guarantee themselves a safe return, and do not internalize the forgone residual claim which accrues to the bank if it is continued. Under this interpretation, improving secondary market liquidity makes the banking sector less stable, and destroys welfare through frequent banking crises.

\section{Opacity vs. Diversification}

A useful benchmark for our analysis is the full information case. In the full information case, we consider that at date 1 the two signals that perfectly reveal the return of banks' projects, $R_{i}$ and $R_{j}$, are observed by both investors. This case is informative about the relative importance of diversification and opacity motives in banks' decision to have interdependent portfolios, and the implications for financial crisis.

As in the main specification of our model, we start by analyzing investors' continuation decision. For each portfolio allocation, $\phi^{F I} \in(0,1)$, and each face value of debt, $D^{F I}$, set at date 0 under full information, the optimal continuation decision that investor $I$ takes at date 1 must satisfy

$$
s_{I}^{* / F I}=\arg \max \left\{s_{I}^{F I} \cdot D^{F I} \cdot \operatorname{Pr}\left(D^{F I} \leq V_{i}\left(\phi^{F I}\right) \mid R_{i}, R_{j}\right)+\left(1-s_{I}^{F I}\right) \cdot r\right\} .
$$


Since at date 1 the investor is perfectly informed, he continues funding the bank when the return of his bank's portfolio is sufficiently high to repay the face value of debt $D^{F I}$. In other words, his continuation strategy is given by

$$
s_{I}^{* / F I}\left(R_{i}, R_{j}\right)=\left\{\begin{array}{ll}
1 & \text { if } V_{i}\left(\phi^{F I}\right) \geq D^{F I} \\
0 & \text { if } V_{i}\left(\phi^{F I}\right)<D^{F I}
\end{array} .\right.
$$

To parallel the imperfect information case, we use $R^{* / F I} \equiv \operatorname{Pr}\left(V_{i}\left(\phi^{F I}\right)<D^{F I}\right)$ to denote the probability that the investor liquidates the bank at date 1 . In contrast with the case when they have information only about their bank's project, with full information investors liquidation decision is perfectly accurate. That is, investors liquidate the bank only in the states in which the bank defaults at date 2, and, similarly, they continue the bank only in the states in which the banks is able to repay the face value of debt.

With full information, investor's $I$ expected payoff at date 0 , is given by

$$
W_{I}^{F I}=\mathbb{E}_{R_{i}, R_{j}}\left\{s_{I}^{* / F I}\left(R_{i}, R_{j}\right) \cdot D^{F I}+\left(1-s_{I}^{* / F I}\left(R_{i}, R_{j}\right)\right) \cdot r\right\}
$$

and the optimal face value of debt solves

$$
D^{* / F I}=\arg \max \left\{D^{F I} \cdot \operatorname{Pr}\left(D^{F I} \leq V_{i}\left(\phi^{F I}\right)\right)+r \cdot\left(1-\operatorname{Pr}\left(D^{F I} \leq V_{i}\left(\phi^{F I}\right)\right)\right)\right\} .
$$

The solution to (11) ensures that when the investor continues the bank, he will receive $D^{* / F I}>$ $r$.

We then turn to analyze each bank's decision about what fraction, $\phi^{F I}$, of their loans to retain in her portfolio. As in the imperfect information case, when banks choose their optimal portfolio, they take into account that the investors make optimal decisions. Thus for each $\phi^{F I}$, and $s_{I}^{* / F I}$ and $D^{* / F I}$ associated with $\phi^{F I}$, the bank $i$ 's expected payoff is

$$
W_{i}^{F I}=\mathbb{E}_{R_{i}, R_{j}}\left\{\max \left[\left(\phi R_{i}+(1-\phi) R_{j}-D^{* / F I}\right), 0\right] \cdot s_{I}^{* / F I}\left(R_{i}, R_{j}\right)\right\} .
$$

Thus, the optimal portfolio allocation, $\phi^{* / F I}$ solves 


$$
\phi^{* / F I}=\arg \max \left\{\mathbb{E}_{R_{i}, R_{j}}\left[\left(\phi R_{i}+(1-\phi) R_{j}-D^{* / F I}\right) \mid D^{* / F I} \leq V_{i}\left(\phi^{F I}\right)\right] \cdot \operatorname{Pr}\left(D^{* / F I} \leq V_{i}\left(\phi^{F I}\right)\right)\right\}
$$

The social planner optimization problem is similar to the incomplete information case. Total welfare aggregates banks' and investors' expected payoffs as of date 0, and can be written as

$$
W^{S / F I}=\mathbb{E}_{R_{i}, R_{j}}\left[\left(\phi R_{i}+(1-\phi) R_{j}\right) \mid D^{* / F I} \leq V_{i}\left(\phi^{F I}\right)\right] \operatorname{Pr}\left(D^{* / F I} \leq V_{i}\left(\phi^{F I}\right)\right)+r\left(1-\operatorname{Pr}\left(D^{* / F I} \leq V_{i}\left(\phi^{F I}\right)\right)\right)
$$

The social planner chooses a fraction of the project, $\phi^{S}$, that each bank retains to maximize (12), given that the face value of debt satisfies (11) and investors take optimal continuation decisions that satisfy (9).

Next we characterize the equilibrium portfolio allocation, as well as the portfolio allocation that maximizes welfare when investors are fully informed at date 1.

Proposition 4 There exists $r_{H}$ such that for any $r<r_{H}, \phi^{* / F I}=\max \left\{\frac{3-2 r}{5}, \frac{1+2 r}{3}\right\}$. If $r \geq r_{H}$, banks have independent portfolios in equilibrium and $\phi^{* / F I}=1$.

Note that for any portfolio allocation $(\phi, 1-\phi)$ that is an equilibrium, the portfolio allocation $(1-\phi, \phi)$ is also an equilibrium. This follows from the symmetry of the banks' portfolio return distribution in the full information case.

Proposition 4 implies that diversification is beneficial for a bank as long as the reservation value of the investor, $r$, is not too high. Although the probability of liquidation increases when banks forego diversification, the face value of debt increases by less when $r$ is high. This implies that banks are able to retain more of the realized return from their portfolios, conditional on being continued. Mathematically, it is sufficient to note that each bank essentially holds a call option contingent on its portfolio return, with a strike price of $D^{* / F I}$. In the full information case, bank $i$ 's expected payoff is the expected value of the option, which is convex in the bank's portfolio return $V_{i}\left(\phi^{F I}\right)$. In consequence, the optimal portfolio allocation that the bank choose will always be a corner solution, depending on which interval the bank's payoff is evaluated.

When investors are perfectly informed about their bank's portfolio return, banks have an incentive to exchange projects only to benefit from diversification. To shed light on how opacity 


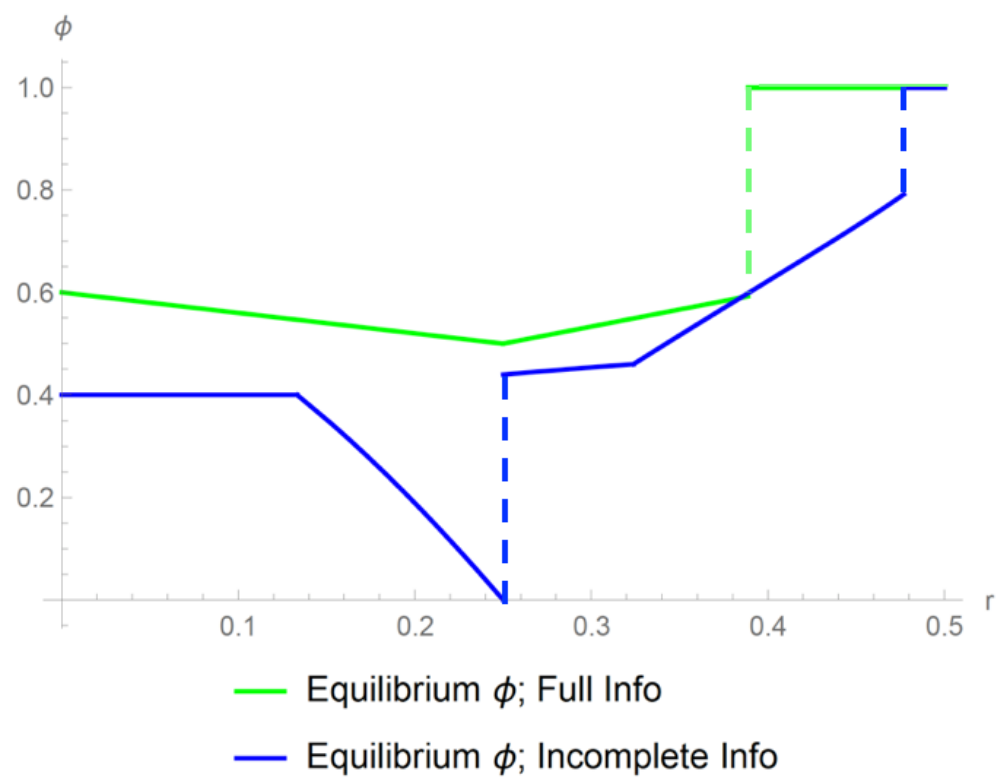

Figure 4: The figure illustrates the equilibrium portfolio allocation under full information, $\phi^{* / F I}$, as well as the equilibrium portfolio allocation under incomplete information, $\phi^{*}$, as a function of the investors' reservation value $r$.

affects banks' decisions to have interdependent portfolio, it is then useful to compare the portfolio allocations that banks choose when they seek to gain from diversification alone, with the allocations that banks choose when they benefit from both opacity and diversification. Figure 4 illustrates how the equilibrium allocation under full information, $\phi^{* / F I}$, compares with the equilibrium allocation under incomplete information, $\phi^{*}$, as a function of the investors' reservation value $r$. It is immediate from the figure that when investors have only access to partial information, banks hold interconnected portfolios beyond what is beneficial for diversification purposes, deliberately creating opacity for their investors.

Proposition 5 There exists $r_{L}$ such that for any $r<r_{L}$, welfare is maximized when banks have correlated portfolios and $\phi^{S / F I}=\phi^{* / F I}=\frac{3-2 r}{5}$. If $r \geq r_{L}$, welfare is maximized when banks have independent portfolio and $\phi^{S / F I}=1$.

Just as in the equilibrium result, note that for any portfolio allocation $(\phi, 1-\phi)$ that is welfare optimal, the portfolio allocation $(1-\phi, \phi)$ is also welfare optimal. This also follows from the symmetry of the banks' portfolio return distribution in the full information case. 


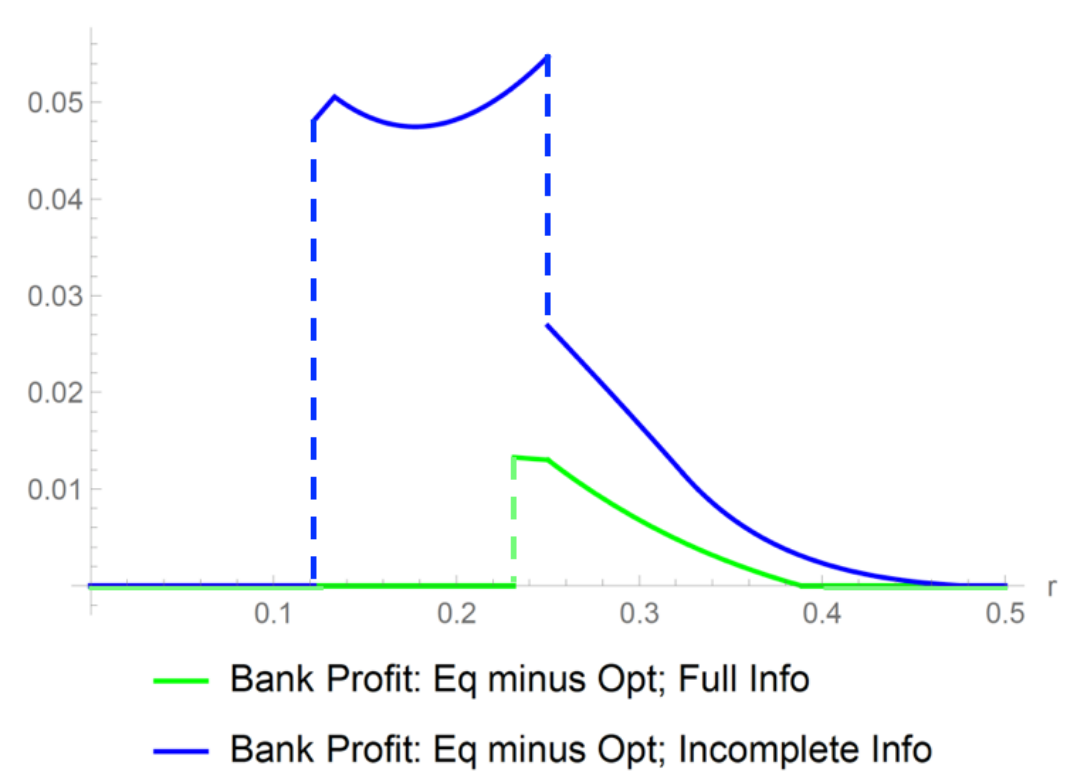

Figure 5: The figure illustrates the difference between the payoff that a bank obtains in equilibrium and the payoff that a banks obtains when she holds the efficient portfolio under full information, as well as under incomplete information, as a function of the investors' reservation value $r$.

Proposition 5 shows that diversification is optimal only if the reservation value of the investor, $r$, is sufficiently low. Since $r_{l}<r_{L}<r_{m}$, even with full information, the equilibrium is inefficient if $r \in\left(r_{L}, r_{m}\right)$. The nature of inefficiency is, however, different than in our main specification when investors have only partial information. When investors have access to full information about their bank's portfolio, banks choose interdependent portfolios not to dilute investor information, but to gain from diversification. However, the bank, just as in the partial information case, does not internalize that if it is not continued, the liquidation value $r$ still accrues to investors. For the social planner on the other hand, the early liquidation payoff represents a welfare gain even when a bank defaults. This is the only wedge that arises between the social planner and the bank in the full information case.

As we discussed in Section 3, opacity introduces a second wedge that renders banks' portfolios inefficient. Banks significantly exploit the informational disadvantage of the investors to increase their profits relative to what they would obtain if they held the optimal portfolio, as it is illustrated in Figure 5. Moreover, the region of inefficiency is wider in the partial information case than in the full information case, as the same figure shows. 
The next proposition characterizes formally the main source of inefficiency when investors have perfect information, with implications for the probability of financial crises.

Proposition 6 For any $r \in\left(r_{L}, r_{H}\right)$ banks portfolio allocations are inefficient. Moreover, the investors continue their bank too frequently, or $R^{* / F I}\left(\phi^{* / F I}\right)<R^{* / F I}(1)$.

It is interesting to contrast the result in Proposition 6 with the result in Proposition 3. With full information about both project realizations, investors terminate their bank whenever the total ex-post return is below the face value they are promised to get. Perfectly informed investors are able to better tailor their joint $\left(D^{* / F I}, R^{* / F I}\right)$ decision to minimize the loss in the event of bad realizations, while capturing as much surplus as possible. Thus, in the absence of

opacity, banks cannot benefit from financial crises. While banking crises occur in equilibrium, they are not as frequent as it would be the case if portfolio allocation were optimal. Only under opacity banks purposefully inflict crises in order to boost profits while they operate.

\section{Conclusion}

We explore a model in which banks strategically hold interconnected portfolios rendering the financial system opaque and more prone to financial crises. In our set-up, banks borrow funds from investors to finance risky projects, in exchange for risky long-term debt contracts. Before maturity investors observe a signal about their bank's project, and decide whether they liquidate their debt early against a fixed redemption value. Ex-ante, each bank can affect how investors use their information by exchanging a fraction of their project with another bank, thus creating opaque portfolios.

We show that generically, banks choose portfolios which are neither extremely opaque nor fully transparent. In other words, they provide investors with an optimal level of information. Furthermore, banks can choose a degree of opacity which makes equilibrium outcome constraint inefficient. However, rather counter-intuitively, the equilibrium degree of opacity does not deem the banks interim safe but ex-post in trouble. Instead, banks choose a degree of opacity that encourages crises: banks make themselves exposed to frequent termination if in return they end up paying extreme low returns to investors if they survive and become profitable. In other words, banks choose to expose themselves to financial crisis. 


\section{References}

Adrian, Tobias, and Markus K. Brunnermeier, 2016, CoVaR, American Economic Review 106, $1705-1741$.

Allen, Franklin, Ana Babus, and Elena Carletti, 2012, Asset commonality, debt maturity and systemic risk, Journal of Financial Economics 104, 519-534.

Allen, Franklin, and Douglas Gale, 1994, Limited market participation and volatility of asset prices, The American Economic Review 84, 933-955.

Alvarez, Fernando, and Gadi Barlevy, 2015, Mandatory disclosure and financial contagion, working paper University of Chicago.

Asriyan, Vladimir, Dana Foarta, and Victoria Vanasco, 2018, Strategic complexity when seeking approval, Technical report, Stanford University, Graduate School of Business.

Azarmsa, Ehsan, and Lin William Cong, 2018, Persuasion in relationship finance, Technical report, Available at SSRN.

Bouvard, Matthieu, Pierre Chaigneau, and Adolfo de Motta, 2015, Transparency in the financial system: Rollover risk and crises, The Journal of Finance 70, 1805-1837.

Chemla, Gilles, and Christopher A. Hennesy, 2014, Skin in the game and moral hazard, The Journal of Finance 69, 1597-1641.

Dang, Tri Vi, Gary Gorton, Bengt Holmstrm, and Guillermo Ordoñez, 2017, Banks as secret keepers, American Economic Review 107, 1005-1029.

DeMarzo, Peter M., 2004, The pooling and tranching of securities: A model of informed intermediation, Review of Financial Studies 18, 1-35.

Dewatripont, Mathias, and Jean Tirole, 2018, Liquidity regulation, bail-ins and bailouts.

Diamond, Douglas W., 1984, Financial intermediation and delegated monitoring, The Review of Economic Studies 51, 393.

Duffie, Darrell, 2008, Innovations in credit risk transfer: Implications for financial stability, BIS Working Papers No 255. 
Egan, Mark, Ali Hortaçsu, and Gregor Matvos, 2017, Deposit competition and financial fragility: Evidence from the US banking sector, American Economic Review 107, 169-216.

Flannery, Mark J., Simon H. Kwan, and Mahendrarajah Nimalendran, 2013, The 2007-2009 financial crisis and bank opaqueness, Journal of Financial Intermediation 22, 55-84.

Gennaioli, Nicola, and Andrei Shleifer, 2018, A Crisis of Beliefs: Investor Psychology and Financial Fragility (Princeton University Press).

Glode, Vincent, Christian C Opp, and Xingtan Zhang, 2018, Voluntary disclosure in bilateral transactions, Journal of Economic Theory 175, 652-688.

Goldstein, Itay, and Yaron Leitner, 2018, Stress tests and information disclosure, Journal of Economic Theory 177, 34-69.

Ibragimov, Rustam, Dwight Jaffee, and Johan Walden, 2011, Diversification disasters, Journal of Financial Economics 99, 333-348.

Jiang, Liangliang, Ross Levine, and Chen Lin, 2016, Competition and bank opacity, Review of Financial Studies 29, 1911-1942.

Matutes, Carmen, and Xavier Vives, 1996, Competition for deposits, fragility, and insurance, Journal of Financial Intermediation 5, 184-216.

Mondria, Jordi, Thomas Wu, and Yi Zhang, 2010, The determinants of international investment and attention allocation: Using internet search query data, Journal of International Economics 82, 85-95.

Morgan, Donald P, 2002, Rating banks: Risk and uncertainty in an opaque industry, American Economic Review 92, 874-888.

Orlov, Dmitry, Pavel Zryumov, and Andrzej Skrzypacz, 2017, Design of macro-prudential stress tests, Stanford University Graduate School of Business Research Paper No. 17-41.

Shaffer, Sherrill, 1994, Pooling intensifies joint failure risk, Research in Financial Services 6, 249-280. 
Vanasco, Victoria, 2017, The downside of asset screening for market liquidity, The Journal of Finance 72, 1937-1982.

Wagner, Wolf, 2010, Diversification at financial institutions and systemic crises, Journal of Financial Intermediation 19, 373-386. 


\section{A Appendix}

\section{A.1 Incomplete Information Derivations}

Lemma A.1 For any early redemption value $r \in\left(0, \frac{1}{2}\right)$ and any portfolio allocation $(\phi,(1-\phi))$ that banks hold, the probability, $R^{*}$, that an investor liquidates the bank at date 1 , as well as the optimal face value of debt, $D^{*}$, with incomplete information are as follows.

For any $r$,

1. if $0 \leq \phi \leq \min \left\{\frac{2}{5}, \frac{2}{3}\left(2(1-2 r)-\sqrt{(4 r)^{2}-4 r+1}\right)\right\}$, then $D^{*}=\frac{2-\phi}{4}$ and $R^{*}=0$.

2. if $\frac{2}{5} \leq \phi \leq \frac{3}{10}\left(1-2 r+\sqrt{1-4 r-6 r^{2}}\right)$, then $D^{*}=\sqrt{\frac{2}{3} \phi(1-\phi)}$ and $R^{*}=0$.

3. if $\max \left\{\frac{2}{3}\left(2(1-2 r)-\sqrt{(4 r)^{2}-4 r+1}\right), 1-\frac{1}{4 r}\right\}<\phi \leq \frac{1}{6}(1-r+\sqrt{r(r+10)+1})$ then $D^{*}=\frac{1}{6}(1+\sqrt{1+12 r(1-\phi)})$ and $R^{*}=\frac{1}{3 \phi}(-4+3 \phi+\sqrt{1+12 r(1-\phi)}), 0<R^{*}<1$.

4. if $\max \left\{\frac{3}{10}\left(1-2 r+\sqrt{1-4 r-6 r^{2}}\right), \frac{1}{6}(1-r+\sqrt{r(r+10)+1})\right\}<\phi \leq 1$, then $D^{*}$ is the largest root of equation

$$
-4 D^{3}+D^{2}(2 r+\phi+1)+r^{2}(\phi-1)=0,
$$

and $R^{*}=\frac{1}{\phi}\left(D^{*}-(1-\phi)\left(1-\frac{r}{D^{*}}\right)\right), 0<R^{*}<1$.

5. if $0 \leq \phi<1-\frac{1}{4 r}$, then $R^{*}=1$.

Proof. Start from equations (3) and (6), letting $G \sim U[0,1]$. We will consider $R^{*}=0, R^{*}=1$ and $0<R^{*}<1$ separately. Moreover, from equation (6), we need to consider the following cases separately $D^{*}<\phi$, and $D^{*} \geq \phi$. The distinction is that in the former case, lender $I$ takes into account that even if the opaque part of portfolio of bank $i,(1-\phi) R_{j}$ returns zero, for sufficiently high realizations of $R_{i}, \frac{D^{*}}{\phi} \leq R_{i} \leq 1$, the lender will get paid if he chooses to continue the bank.

1. No early liquidation, $R^{*}=0$.

(a) $\frac{D^{*}}{\phi}>1$. In this case, investor payoff simplifies to

$$
W_{I}=D \int_{0}^{1}\left(1-\frac{D-\phi z}{1-\phi}\right) d z
$$


The first order condition is

$$
\frac{4 D+\phi-2}{2(\phi-1) \phi}=0
$$

which implies

$$
D^{*}=\sqrt{\frac{1}{4}(2-\phi)} .
$$

The second order condition holds $(\mathrm{SOC}<0)$, thus the above $D^{*}$ is a maximum. $D^{*}>\phi$ requires $0 \leq \phi \leq \frac{2}{5}$, while $R^{*}=0$ requires $\phi \leq \frac{3}{10}\left(1-2 r+\sqrt{1-4 r-6 r^{2}}\right)$, which leads the first case.

(b) $\frac{D^{*}}{\phi}<1$. In this case, investor payoff simplifies to

$$
W_{I}=\int_{0}^{\frac{D}{\phi}}\left(1-\frac{D-\phi z}{1-\phi}\right) d z+D\left(1-\frac{D}{\phi}\right)
$$

The first order condition is

$$
\frac{3 D^{2}+2(\phi-1) \phi}{2(\phi-1) \phi}=0
$$

which implies

$$
D^{*}=\sqrt{\frac{2}{3} \phi(1-\phi)} .
$$

The second order condition holds $(\mathrm{SOC}<0)$, thus the above $D^{*}$ is a maximum. $D^{*}<\phi$ requires $\phi \geq \frac{2}{5}$, while $R^{*}=0$ requires $\phi \leq \frac{3}{10}\left(1-2 r+\sqrt{1-4 r-6 r^{2}}\right)$, which leads the second case.

2. Some early liquidation, $0<R^{*}<1$.

From equation $(3), R^{*}=\frac{D}{\phi}-\frac{1-\phi}{\phi}\left(1-\frac{r}{D}\right)$. We again separately consider two cases:

(a) $\frac{D^{*}}{\phi}>1$. In this case, investor payoff simplifies to

$$
W_{I}=D \int_{R^{*}}^{1}\left(1-\frac{D-\phi z}{1-\phi}\right) d z+r R^{*}
$$


Substituting for $R^{*}$ and taking first order condition implies

$$
\frac{(D(1-3 D)+r(1-\phi))(r(1-\phi)-D(1-D))}{2 \phi(1-\phi) D^{2}}=0
$$

This is a quadratic equation with four roots: $D_{1}=\frac{1}{6}(1-\sqrt{1+12 r(1-\phi)})<0$. $D_{2,4}=$ $\frac{1}{2}(1 \pm \sqrt{4 r \phi-4 r+1})$, and $R^{*}\left(D_{2}\right)=R^{*}\left(D_{4}\right)=1$. Thus, the only relevant face value is $D_{3}=\frac{1}{6}(1+\sqrt{1+12 r(1-\phi)})$. Note that $R^{*}(D)<1$ only if $D_{2}<D<D_{4}$, thus the optimal face value can be in this interval. Moreover, $D_{2}<D_{3}<D_{4}$.

Next, the second order condition is given by

$$
\frac{\frac{r^{2}(1-\phi)^{2}}{D^{3}}+3 D-2}{(1-\phi) \phi}
$$

Letting $\mathrm{SOC}=0$ leads to a quadratic equation. Only two of the roots are in between $D_{2}$ and $D_{3}$, and $D_{2}<D_{1}^{s o c}<D_{3}<D_{2}^{s o c}<D_{4}$. Thus the second order condition changes sign twice on the interval $\left[D_{2}, D_{4}\right]$. Moreover, the second derivative evaluated at $D_{2}$ and $D_{4}$ is

$$
\frac{1 \pm(\sqrt{1-4 r(1-\phi)})(1-4 r(1-\phi))}{2 r \phi(1-\phi)^{2}}>0
$$

which implies that $D_{2}$ and $D_{4}$ are local minima, and that the second derivative is negative at $D_{3}$, thus $D_{3}$ is a (local) maximum. Since first order condition is positive between $D_{2}$ and $D_{3}$, and negative between $D_{3}$ and $D_{4}, D_{3}$ is the global maximum in the interval $\left[D_{2}, D_{4}\right]$. Thus we have

$$
\begin{aligned}
D^{*} & =\frac{1}{6}(1+\sqrt{1+12 r(1-\phi)}) \\
R^{*} & =\frac{1}{3 \phi}(-4+3 \phi+\sqrt{1+12 r(1-\phi)}) .
\end{aligned}
$$

Lastly, $D^{*}>\phi$ requires $\phi<\frac{1}{6}\left(1-r+\sqrt{r^{2}+10 r+1}\right), R^{*}<1$ requires $\phi>1-\frac{1}{4 r}$ and $R^{*}>0$ requires $\phi>\frac{2}{3}\left(2(1-2 r)-\sqrt{(4 r)^{2}-4 r+1}\right)$. This leads the third case.

Moreover, $R^{*}$ cannot exceed 1 , thus $R^{*}=1$ if $\phi \geq 1-\frac{1}{4 r}$, which leads the fifth case.

(b) $\frac{D^{*}}{\phi}<1$. Here we need to consider two sub-cases 
(i) $R^{*}<\frac{D^{*}}{\phi} \Leftrightarrow r<D^{*}<\phi$. In this case, investor payoff simplifies to

$$
W_{I}=\int_{R^{*}}^{\frac{D}{\phi}}\left(1-\frac{D-\phi z}{1-\phi}\right) d z+D\left(1-\frac{D}{\phi}\right)+r R^{*}
$$

Substituting for $R^{*}$ and taking the first order condition implies

$$
\frac{-4 D^{3}+D^{2}(1+\phi+2 r)-r^{2}(1-\phi)}{2 D^{2} \phi}=0
$$

The numerator is a cubic function in $D$, with $\Delta=-432 r^{4}(1-\phi)^{2}+4 r^{2}(1-\phi)(1+$ $\phi+2 r)^{3}$, thus $\Delta<0$ implies $(1+\phi+2 r)^{3}-108 r^{2}(1-\phi)<0$. For any pair $(r, \phi)$ that satisfy $\Delta<0$,

$$
\phi<\tilde{\phi}(r)=\max \left\{\frac{3}{10}\left(1-2 r+\sqrt{1-4 r-6 r^{2}}\right), \frac{1}{6}(-r+\sqrt{r(r+10)+1}+1)\right\}
$$

and $(r, \phi)$ is covered by one of the first 3 cases. Thus when $\phi>\tilde{\phi}(r), \operatorname{Delta}>0$ and the cubic first order condition has 3 distinct real roots, $D_{1}<D_{2}<D_{3}$. $D_{1}<0$, so it is not the solution. Moreover, note that the derivative of investors surplus approaches $-\infty$ as $D \rightarrow 0$ from above, and as $D \rightarrow \infty$.

Next, the second order condition is given by

$$
\frac{r^{2}(1-\phi)-2 D^{3}}{D^{3} \phi}
$$

which has one root: $D^{s o c}=\left(\frac{r^{2}(1-\phi)}{2}\right)^{\frac{1}{3}}$, and it is positive iff $D<D^{s o c}$. Moreover, $D_{2}<D^{s o c}<D_{3}$, thus $D_{2}$ is a local minimum while $D_{3}$ is a local maximum. Thus either $D_{3}$ is the optimal face value, or the minimum feasible $D$, which in this case is $D=r$. Comparing the two values leads $W_{I}\left(\phi, r, D_{3}\right)>W_{I}(\phi, r, r), \forall \phi>\tilde{\phi}(r)$. Thus we have

$$
\begin{aligned}
D^{*} & =D_{3} \\
R^{*} & =\frac{1}{\phi}\left(D^{*}-(1-\phi)\left(1-\frac{r}{D^{*}}\right)\right) .
\end{aligned}
$$

Lastly, note that if $D^{*}=r$, first order condition implies that $\phi=r$. However, 
$r<\tilde{\phi}(r)$, which in turn implies that whenever $\frac{D^{*}}{\phi}<1, D^{*}>r$ and thus the next case is never relevant.

(ii) $R^{*}>\frac{D^{*}}{\phi} \Leftrightarrow D^{*}<\min \{r, \phi\}$. As argued above, this case does not arise in equilibrium.

Lastly, if $D^{*}=\phi$, first order condition implies $\phi=\frac{1}{6}(1-r+\sqrt{r(r+10)+1})$, and $R^{*}>0$ implies $\phi>\frac{3}{10}\left(1-2 r+\sqrt{1-4 r-6 r^{2}}\right)$. This leads to the forth case.

\section{Always liquidate.}

This case is covered in treatment of 2 .(a), some early liquidation with $\frac{D^{*}}{\phi}>1$.

\section{Proof of Proposition 1}

We need to calculate the optimal $\phi$ for a bank $i$. That is, $\phi$ that maximizes

$$
W_{i}=\int_{R^{*}}^{1} \int_{\max \left\{\frac{D^{*}-\phi R_{i}}{1-\phi}, 0\right\}}^{1}\left(\phi R_{i}+(1-\phi) R_{j}-D^{*}(\phi)\right) d R_{j} d R_{i}
$$

As the optimal face value of debt changes depending on $\phi$ and $r$, we need to consider various cases, as defined in lemma A.1.

Case 1: $0 \leq \phi \leq \min \left\{\frac{2}{5}, \frac{2}{3}\left(2(1-2 r)-\sqrt{(4 r)^{2}-4 r+1}\right)\right\}$.

Here $D^{*}=\frac{2-\phi}{4}$ and $R^{*}=0$. Substitute in the planner objective function to get

$$
W_{i}=\frac{7 \phi^{2}+12(1-\phi)}{96(1-\phi)}
$$

Since $R^{*}=0$, the optimal face value and bank profit are independent of $r$. Observe that $\frac{d W_{i}}{d \phi}>0$ and $\frac{d^{2} W_{i}}{d \phi^{2}}>0$, thus the bank profit function is increasing and convex in this region. It follows that if the equilibrium level of opacity is in this region we will have

$$
\phi^{*}=\min \left\{\frac{2}{5}, \frac{2}{3}\left(2(1-2 r)-\sqrt{(4 r)^{2}-4 r+1}\right)\right\}
$$




$$
\phi^{*}= \begin{cases}\frac{2}{5} & \text { if } 0<r<\frac{2}{15} \\ \frac{2}{3}\left(2(1-2 r)-\sqrt{(4 r)^{2}-4 r+1}\right) & \text { if } \frac{2}{15}<r<\frac{1}{4}\end{cases}
$$

Case 2: $\frac{2}{5} \leq \phi \leq \frac{3}{10}\left(1-2 r+\sqrt{1-4 r-6 r^{2}}\right)$

Here $D^{*}=\sqrt{\frac{2}{3} \phi(1=\phi)}$ and $R^{*}=0$. Substitute in the bank objective function to get

$$
W_{i}=\frac{1}{2}-\frac{8}{9} \sqrt{\frac{2}{3}(1-\phi) \phi}
$$

Since $R^{*}=0$, again the optimal face value and bank profit are independent of $r$. Observe that $\frac{d W_{i}}{d \phi}=0$ at $\phi=\frac{1}{2}$ and $\frac{d^{2} W_{i}}{d \phi^{2}}>0$, thus the objective function is convex, and the maximum is attained on one of the corners, i.e. $\phi^{*}=\frac{2}{5}$ or $\phi^{*}=\frac{3}{10}\left(1-2 r+\sqrt{1-4 r-6 r^{2}}\right)$. Direct comparison of the bank profit on the two boundaries reveals that $W_{i}\left(\frac{2}{5}\right) \geq W_{i}\left(\frac{3}{10}\left(1-2 r+\sqrt{1-4 r-6 r^{2}}\right)\right)$ for $0<r<\frac{2}{15}$. It follows that if the equilibrium level of opacity is in this region we will have

$$
\phi^{*}=\frac{2}{5}
$$

Case 3: $\max \left\{\frac{2}{3}\left(2(1-2 r)-\sqrt{(4 r)^{2}-4 r+1}\right), 1-\frac{1}{4 r}\right\}<\phi \leq \frac{1}{6}(1-r+\sqrt{r(r+10)+1})$. Here, $D^{*}=\frac{1}{6}(1+\sqrt{1+12 r(1-\phi)})$ and $R^{*}=\frac{1}{3 \phi}(-4+3 \phi+\sqrt{1+12 r(1-\phi)}), 0<$ $R^{*}<1$. Substitute in the bank objective function to get

$$
W_{i}=\frac{144 r(1-\phi)-(42 r(1-\phi)+23) \sqrt{12 r(1-\phi)+1}+31}{162(1-\phi) \phi}
$$

It is more convenient to consider $r<\frac{1}{4}$ and $r>\frac{1}{4}$ separately. When $\frac{2}{15}<r<\frac{1}{4}, \frac{d^{2} W_{i}}{d \phi^{2}}>0$. Since the bank objective is convex, maximum is attained at one of the two boundaries. Direct comparison reveals that $W_{i}\left(\frac{2}{3}\left(2(1-2 r)-\sqrt{(4 r)^{2}-4 r+1}\right)\right)>W_{i}\left(\frac{1}{6}(1-r+\sqrt{r(r+10)+1})\right)$. On the other hand, when $\frac{1}{4}<r<\frac{1}{2}, \frac{d W_{i}}{d \phi}>0$. Since the bank objective is increasing in $\phi$, maximum bank profit is attained at maximum relevant $\phi$, i.e. $\frac{1}{6}(1-r+\sqrt{r(r+10)+1})$. 
Thus if the equilibrium level of bank opacity is in this region, we have

$$
\phi^{*}= \begin{cases}\frac{2}{3}\left(2(1-2 r)-\sqrt{(4 r)^{2}-4 r+1}\right) & \text { if } \frac{2}{15}<r<\frac{1}{4} \\ \frac{1}{6}(1-r+\sqrt{r(r+10)+1}) & \text { if } \frac{1}{4}<r<\frac{1}{2}\end{cases}
$$

Case 4: $\max \left\{\frac{3}{10}\left(1-2 r+\sqrt{1-4 r-6 r^{2}}\right), \frac{1}{6}(1-r+\sqrt{r(r+10)+1})\right\}<\phi \leq 1$.

Here, $D^{*}$ is the largest root of equation

$$
-4 D^{3}+D^{2}(2 r+\phi+1)+r^{2}(\phi-1)=0,
$$

and $R^{*}=\frac{1}{\phi}\left(D^{*}-(1-\phi)\left(1-\frac{r}{D^{*}}\right)\right), 0<R^{*}<1$. Bank profit is given by

$$
W_{i}^{\text {case } 4}=W_{i}=\frac{3 D^{* 5}-3 D^{* 4}(\phi+1)+D^{* 3}\left(\phi^{2}+\phi+1\right)-r^{3}(1-\phi)^{2}}{6 D^{* 3} \phi} .
$$

We will use $W_{i}^{\text {case } 4}$ for the objective function in this region since we use it to define the equilibrium thresholds.

We consider two cases separately, when $r<\frac{2}{15}$ and when $r>\frac{2}{15}$

- $\mathrm{r}<\frac{2}{15}$ :

In this region, $\frac{d^{2} W_{i}^{\text {case } 4}}{d \phi^{2}}>0, \forall \phi>\frac{3}{10}\left(1-2 r+\sqrt{1-4 r-6 r^{2}}\right)$, thus the objective function is convex and the maximum is attained at one of the two boundaries. The upper boundary is $\phi=1$ and the lower boundary is $\phi=\frac{3}{10}\left(1-2 r+\sqrt{1-4 r-6 r^{2}}\right)$. The bank profit at the two boundaries is given by

$$
\begin{aligned}
& W_{i}\left(\frac{3}{10}\left(1-2 r+\sqrt{1-4 r-6 r^{2}}\right)\right)= \\
& \quad \frac{1}{2}-\frac{8}{45} \sqrt{2(\sqrt{1-2 r(3 r+2)}+1)+r(3 r+6 \sqrt{1-2 r(3 r+2)}+2)}, \\
& W_{i}(1)=\frac{(1-r)^{2}}{8} .
\end{aligned}
$$

Where the first expression uses continuity of bank objective function on the boundary $\frac{3}{10}\left(1-2 r+\sqrt{1-4 r-6 r^{2}}\right)$, and case 2 above. Direct comparison of the two expressions 
reveals that the former expression is always larger than the latter. Thus in this range

$$
\phi^{*}=\frac{3}{10}\left(1-2 r+\sqrt{1-4 r-6 r^{2}}\right)
$$

- $\mathrm{r}>\frac{2}{15}$ :

Consider the first order condition

$$
\frac{d W_{i}^{\text {case }} 4(\phi, r)}{d \phi}=0
$$

The first order condition has either one or two solutions for $r \in\left(\frac{2}{15}, \frac{1}{2}\right)$. Let $\phi_{1}$ denote the larger solution. $\phi_{1}$ exists for all $r \in\left(\frac{2}{15}, \frac{1}{2}\right), \phi_{1}>\frac{1}{6}(1-r+\sqrt{r(r+10)+1})$, and $\frac{d^{2} W_{i}^{\text {case }} 4(\phi, r)}{d \phi^{2}}>0$, i.e. $\phi_{1}$ is a minimum.

Let $\phi_{2}$ denote the smaller solution (if it exists). $\phi_{2}$ exists only if $r>\hat{r} \in\left(\frac{2}{15}, \frac{1}{5}\right)$, and $\frac{d^{2} W_{i}^{\text {case }}(\phi, r)}{d \phi^{2}}<0$, i.e. $\phi_{1}$ is a maximum. However, $\phi_{2}$ is not always larger than $\frac{1}{6}(1-r+\sqrt{r(r+10)+1})$, thus it is not always a relevant solution. Moreover, $\frac{d \phi_{2}}{d r}>0$.

Let $\phi_{F O C}^{*}=\phi_{2}$, and let $r_{z}$ denote the level of $r \in\left(\frac{1}{4}, \frac{1}{2}\right)$ such that $\phi_{F O C}^{*}(r)=\frac{1}{6}(1-r+\sqrt{r(r+10)+1})$. Thus for $r>r_{z}, \phi_{F O C}^{*}$ is an interior (local) maximum.

Given the above argument, for $r \in\left(\frac{2}{15}, r_{z}\right)$, bank objective function is either decreasing or convex (or both) for $\phi \in\left(\frac{1}{6}(1-r+\sqrt{r(r+10)+1}), 1\right)$. Thus the maximum is attained at one of the two boundaries. The bank profit at the two boundaries is given by

$$
\begin{gathered}
W_{i}\left(\frac{1}{6}(1-r+\sqrt{r(r+10)+1})\right)= \\
\frac{46 \sqrt{2 r(r-\sqrt{r(r+10)+1}+5)+1}+2 r(r-\sqrt{r(r+10)+1}+5)(7 \sqrt{2 r(r-\sqrt{r(r+10)+1}+5)+1}-24)-62}{9(-r+\sqrt{r(r+10)+1}-5)(-r+\sqrt{r(r+10)+1}+1)} \\
W_{i}(1)=\frac{(1-r)^{2}}{8}
\end{gathered}
$$

Where the first expression uses continuity of bank objective function on the boundary $\frac{1}{6}(1-r+\sqrt{r(r+10)+1})$, and case 3 above. Direct comparison of the two expressions reveal that the former expression is larger than the latter when $r \in\left(\frac{2}{15}, r_{z}\right)$. Thus in case 
4 , in this range

$$
\phi^{*}=\frac{3}{10}\left(1-2 r+\sqrt{1-4 r-6 r^{2}}\right)
$$

Next, let $r_{h}$ denote $r \in\left(r_{z}, 1\right)$ such that $W_{i}^{\text {case } 4}\left(\phi_{F O C}^{*}, r\right)=\frac{(1-r)^{2}}{8}=W_{i}(1)$. For any $r \in\left(r_{z}, r_{h}\right)$, bank surplus is first concave and then convex over the interval $\phi \in$ $\left(\frac{1}{6}\left(1-r+\sqrt{r^{2}+10 r+1}\right), 1\right)$, with an interior (local) maximum and a larger interior (local) minimum. Thus the global maximum is obtained at either the local maximum, $\phi_{F O C}^{*}$, or at the upper boundary $\phi=1$. Direct comparison of the corresponding levels of objective functions reveals that $W_{i}^{\text {case } 4}\left(\phi_{F O C}^{*}(r), r\right)>\frac{(1-r)^{2}}{8}=W_{i}(1)$ for $r \in\left(r_{z}, r_{h}\right)$.

Finally, for $r>r_{h}$, the objective function is larger at the corner $\phi=1$ compared to the interior local maximum, thus $\phi^{*}=1$.

Putting the cases together,

$$
\phi^{*}= \begin{cases}\frac{3}{10}\left(1-2 r+\sqrt{1-4 r-6 r^{2}}\right) & \text { if } 0<r<\frac{2}{15} \\ \frac{1}{6}\left(1-r+\sqrt{r^{2}+10 r+1}\right) & \text { if } \frac{2}{15}<r<r_{z} \\ \phi_{F O C}^{*} & \text { if } r_{z}<r<r_{h} \\ 1 & \text { if } r_{h}<r<\frac{1}{2}\end{cases}
$$

Case 5: $0 \leq \phi<1-\frac{1}{4 r}$.

Here $R^{*}=1$, thus $W_{i}=0$.

Comparison across cases. Next for each $r$, we compare the optimum across cases. Again it is easiest to treat 3 ranges separately

1. $0<\mathrm{r}<\frac{2}{15}$ :

Here we compare the maximum across cases 1, 2, and 4. Case 1 shows that when $0<r<\frac{2}{15}$, maximum is attained at $\phi=\frac{2}{5}$. Case 2 shows that $\phi=\frac{2}{5}$ is also optimal in that range. Thus within cases 1 and $2, \phi=\frac{2}{5}$ is optimal.

Case 4 argues that if $r<\frac{2}{15}$, maximum bank profit is attained at $\phi=\frac{3}{10}\left(1-2 r+\sqrt{1-4 r-6 r^{2}}\right)$.

However, case 2 shows that $W_{i}\left(\frac{2}{5}\right) \geq W_{i}\left(\frac{3}{10}\left(1-2 r+\sqrt{1-4 r-6 r^{2}}\right)\right)$. Thus the maximum is attained at $\phi=\frac{2}{5}$. 
2. $\frac{2}{15}<\mathbf{r}<\frac{1}{4}$ :

Here we compare the maximum across cases 1, 3, and 4. Case 1 shows that when $\frac{2}{15}<r<\frac{1}{4}$, maximum is attained at $\phi=\frac{2}{3}\left(2(1-2 r)-\sqrt{(4 r)^{2}-4 r+1}\right)$, which also maximizes bank profit over the region covered by case 3 . The latter implies $W_{i}\left(\frac{2}{3}\left(2(1-2 r)-\sqrt{(4 r)^{2}-4 r+1}\right)\right) \geq W_{i}\left(\frac{1}{6}(1-r+\sqrt{r(r+10)+1})\right.$.

Since $\phi=\frac{1}{6}(1-r+\sqrt{r(r+10)+1})$ maximizes bank profit over the region covered by Case 4 , the maximum is attained at $\phi=\frac{2}{3}\left(2(1-2 r)-\sqrt{(4 r)^{2}-4 r+1}\right)$.

3. $\frac{1}{4}<\mathrm{r}<\frac{1}{2}$

Here we compare the maximum across cases 3, 4, and 5 . Case 3 shows that $W_{i}\left(\frac{1}{6}(1-r+\sqrt{r(r+10)+1})\right) \geq W_{i}\left(1-\frac{1}{4 r}\right)=0$. Comparing with case 4 in this region, and using continuity of the bank profit function at the boundary $\frac{1}{6}(1-r+\sqrt{r(r+10)+1})$ yields

$$
\phi^{*}= \begin{cases}\frac{1}{6}\left(1-r+\sqrt{r^{2}+10 r+1}\right) & \text { if } \frac{1}{4}<r<r_{z} \\ \phi_{F O C}^{*} & \text { if } r_{z}<r<r_{h} \\ 1 & \text { if } r_{h}<r<\frac{1}{2}\end{cases}
$$

Putting all the regions together leads the final result.

$$
\phi^{*}= \begin{cases}\frac{2}{5} & \text { if } 0<r<\frac{2}{15} \\ \frac{2}{3}\left(2(1-2 r)-\sqrt{(4 r)^{2}-4 r+1}\right) & \text { if } \frac{2}{15}<r<\frac{1}{4} \\ \frac{1}{6}\left(1-r+\sqrt{r^{2}+10 r+1}\right) & \text { if } \frac{1}{4}<r<r_{z} \\ \phi_{F O C}^{*} & \text { if } r_{z}<r<r_{h} \\ 1 & \text { if } r_{h}<r<\frac{1}{2}\end{cases}
$$

where $\phi_{F O C}^{*}$ is the solution to $\frac{d W_{i}^{\text {case } 4}(\phi, r)}{d \phi}=0$ with $\left.\frac{d^{2} W_{i}^{\text {case }}{ }^{4}(\phi, r)}{d \phi^{2}}\right|_{\phi_{F O C}^{*}}<0 . r_{z}$ is the value of $r \in\left(\frac{1}{4}, \frac{1}{2}\right)$ such that $\phi_{F O C}^{*}(r)=\frac{1}{6}\left(1-r+\sqrt{r^{2}+10 r+1}\right), r_{z} \approx 0.324$ and $r_{h}>r_{z}$ is the value of $r \in\left(\frac{1}{4}, \frac{1}{2}\right)$ such that $W_{i}^{\text {case } 4}\left(\phi_{F O C}^{*}, r\right)=\frac{(1-r)^{2}}{8}=W_{i}(1), r_{h} \approx 0.477$. 


\section{Proof of Proposition 2}

We need to calculate the optimal $\phi$ for the social planner who faces the same friction as the bank facing the investors. That is, $\phi$ that maximizes

$$
W^{S}=2 \times \int_{R^{*}}^{1}\left[\phi R_{i}\left(1-\max \left\{\frac{D^{*}-\phi R_{i}}{1-\phi}, 0\right\}\right)+(1-\phi) \int_{\max \left\{\frac{D^{*}-\phi R_{i}}{1-\phi}, 0\right\}}^{1} R_{j} d R_{j}\right] d R_{i}+r R^{*}
$$

As the optimal face value of debt changes depending on $\phi$ and $r$, we need to consider various cases, as defined in lemma A.1. Moreover, let

$$
r_{l}=\frac{1}{3}\left(2 \sqrt{\frac{7}{15}}-1\right)
$$

and note that $r_{l}<\frac{2}{15}$. We will use $r_{l}$ later to characterize the optimal $\phi^{S}$.

Case 1: $0 \leq \phi \leq \min \left\{\frac{2}{5}, \frac{2}{3}\left(2(1-2 r)-\sqrt{(4 r)^{2}-4 r+1}\right)\right\}$.

Here $D^{*}=\frac{2-\phi}{4}$ and $R^{*}=0$. Substitute in the planner objective function to get

$$
W^{S}=\frac{13 \phi^{2}+36(1-\phi)}{96(1-\phi)}
$$

Since $R^{*}=0$, the optimal face value and total surplus are independent of $r$. Observe that $\frac{d W^{S}}{d \phi}>0$ and $\frac{d^{2} W^{S}}{d \phi^{2}}>0$, thus the total surplus is increasing and convex in this region. It follows that if the socially optimal level of opacity is in this region we will have

$$
\phi^{S}=\min \left\{\frac{2}{5}, \frac{2}{3}\left(2(1-2 r)-\sqrt{(4 r)^{2}-4 r+1}\right)\right\}
$$

or

$$
\phi^{S}= \begin{cases}\frac{2}{5} & \text { if } 0<r<\frac{2}{15} \\ \frac{2}{3}\left(2(1-2 r)-\sqrt{(4 r)^{2}-4 r+1}\right) & \text { if } \frac{2}{15}<r<\frac{1}{4}\end{cases}
$$

Case 2: $\frac{2}{5} \leq \phi \leq \frac{3}{10}\left(1-2 r+\sqrt{1-4 r-6 r^{2}}\right)$. 
Here $D^{*}=\sqrt{\frac{2}{3} \phi(1=\phi)}$ and $R^{*}=0$. Substitute in the planner objective function to get

$$
W^{S}=\frac{1}{54}(27-4 \sqrt{6(1-\phi) \phi})
$$

Since $R^{*}=0$, again the optimal face value and total surplus are independent of $r$. Observe that $\frac{d W^{S}}{d \phi}=0$ at $\phi=\frac{1}{2}$ and $\frac{d^{2} W^{S}}{d \phi^{2}}>0$, thus the objective function is convex, and the maximum is attained on one of the corners, i.e. $\phi^{S}=\frac{2}{5}$ or $\phi^{S}=\frac{3}{10}\left(1-2 r+\sqrt{1-4 r-6 r^{2}}\right)$. Direct comparison of the planner objective on the two boundaries reveals that $W^{S}\left(\frac{2}{5}\right) \geq$ $W^{S}\left(\frac{3}{10}\left(1-2 r+\sqrt{1-4 r-6 r^{2}}\right)\right)$ for $0<r<\frac{2}{15}$. It follows that if the socially optimal level of opacity is in this region we will have

$$
\phi^{S}=\frac{2}{5}
$$

Case 3: $\max \left\{\frac{2}{3}\left(2(1-2 r)-\sqrt{(4 r)^{2}-4 r+1}\right), 1-\frac{1}{4 r}\right\}<\phi \leq \frac{1}{6}(1-r+\sqrt{r(r+10)+1})$. Here, $D^{*}=\frac{1}{6}(1+\sqrt{1+12 r(1-\phi)})$ and $R^{*}=\frac{1}{3 \phi}(-4+3 \phi+\sqrt{1+12 r(1-\phi)}), 0<$ $R^{*}<1$. Substitute in the planner objective function to get

$$
W^{S}=\frac{6 r(27 \phi-12)(1-\phi)-(17-30 r(1-\phi)) \sqrt{12 r(1-\phi)+1}+37}{162(1-\phi) \phi} .
$$

It is more convenient to consider $r<\frac{1}{4}$ and $r>\frac{1}{4}$ separately. When $\frac{2}{15}<r<\frac{1}{4}, \frac{d^{2} W^{S}}{d \phi^{2}}>0$. Since the planner objective is convex, maximum is attained at one of the two boundaries. Direct comparison reveals that $W^{S}\left(\frac{2}{3}\left(2(1-2 r)-\sqrt{(4 r)^{2}-4 r+1}\right)\right)<W^{S}\left(\frac{1}{6}(1-r+\sqrt{r(r+10)+1})\right)$. On the other hand, when $\frac{1}{4}<r<\frac{1}{2}, \frac{d W^{S}}{d \phi}>0$. Since the planner objective is increasing in $\phi$, maximum welfare is attained at maximum relevant $\phi$, i.e. $\frac{1}{6}(1-r+\sqrt{r(r+10)+1})$.

Thus if socially optimal opacity is in this region, we have

$$
\phi^{S}=\frac{1}{6}(1-r+\sqrt{r(r+10)+1})
$$

Case 4: $\max \left\{\frac{3}{10}\left(1-2 r+\sqrt{1-4 r-6 r^{2}}\right), \frac{1}{6}(1-r+\sqrt{r(r+10)+1})\right\}<\phi \leq 1$.

Here, $D^{*}$ is the largest root of equation

$$
-4 D^{3}+D^{2}(2 r+\phi+1)+r^{2}(\phi-1)=0,
$$


and $R^{*}=\frac{1}{\phi}\left(D^{*}-(1-\phi)\left(1-\frac{r}{D^{*}}\right)\right), 0<R^{*}<1$. The total welfare is given by

$$
W^{S}=\frac{-3 D^{* 5}+6 D^{* 4} r+D^{* 3}(1-6 r(1-\phi)+\phi(1+\phi))+3 D^{* 2} r^{2}(1-\phi)-r^{3}(1-\phi)^{2}}{6 D^{* 3} \phi} .
$$

We consider two cases separately, when $r<\frac{2}{15}$ and when $r>\frac{2}{15}$

- $\mathrm{r}<\frac{2}{15}$ :

In this region, $\frac{d^{2} W^{S}}{d \phi^{2}}>0, \forall \phi>\frac{3}{10}\left(1-2 r+\sqrt{1-4 r-6 r^{2}}\right)$, thus the objective function is convex and the maximum is attained at one of the two boundaries. The upper boundary is $\phi=1$ and the lower boundary is $\phi=\frac{3}{10}\left(1-2 r+\sqrt{1-4 r-6 r^{2}}\right)$. The total surplus at the two boundaries is given by

$$
\begin{aligned}
& W^{S}\left(\frac{3}{10}\left(1-2 r+\sqrt{1-4 r-6 r^{2}}\right)\right)= \\
& \quad \frac{1}{2}-\frac{2}{45} \sqrt{2(\sqrt{1-2 r(3 r+2)}+1)+r(3 r+6 \sqrt{1-2 r(3 r+2)}+2)}, \\
& W^{S}(1)=1 / 8(3+r(2+3 r)) .
\end{aligned}
$$

Where the first expression uses continuity of social planner objective function on the boundary $\frac{3}{10}\left(1-2 r+\sqrt{1-4 r-6 r^{2}}\right)$, and case 2 above. Direct comparison of the two expressions reveal that there exists a threshold $r_{1}, r_{1}<r_{l}<\frac{2}{15}$, such that the two curves cross only once at $r_{1}$, and for $r<\frac{2}{15}, W^{S}\left(\frac{3}{10}\left(1-2 r+\sqrt{1-4 r-6 r^{2}}\right)\right)>W^{S}(1)$ iff $r<r_{1}$. Thus in this range

$$
\phi^{S}= \begin{cases}\frac{3}{10}\left(1-2 r+\sqrt{1-4 r-6 r^{2}}\right) & \text { if } 0<r<r_{1} \\ 1 & \text { if } r_{1}<r<\frac{2}{15}\end{cases}
$$

- $\mathrm{r}>\frac{2}{15}$ :

In this region, there exists two thresholds, $r_{2}$ and $r_{3}$, such that: (1) $\frac{d^{2} W^{S}}{d \phi^{2}}>0, \forall \phi>$ $\frac{1}{6}(1-r+\sqrt{r(r+10)+1})$ iff $\frac{2}{15}<r<r_{2},(2) \frac{d W^{S}}{d \phi}>0, \forall \phi>\frac{1}{6}(1-r+\sqrt{r(r+10)+1})$ iff $r_{3}<r<1$, and (3) $r_{3}<r_{2}$. It follows that for any $r, \frac{2}{15}<r<\frac{1}{2}$, either $\frac{d^{2} W^{S}}{d \phi^{2}}>0$ or $\frac{d W^{S}}{d \phi}>0 \forall \phi>\frac{1}{6}(1-r+\sqrt{r(r+10)+1})$ (or both). Thus the maximum of the objective function is attained at one of the two boundaries. The total surplus at the two 
boundaries is given by

$$
\begin{aligned}
& W^{S}\left(\frac{1}{6}(1-r+\sqrt{r(r+10)+1})\right)= \\
& \frac{2\left(37-\frac{3}{2} r(5+r-\sqrt{r(r+10)+1})(5+3 r-3 \sqrt{r(r+10)+1})\right)}{9(5+r-\sqrt{r(r+10)+1})(1-r+\sqrt{r(r+10)+1})} \\
& +\frac{2 \sqrt{2 r(r-\sqrt{r(r+10)+1}+5)+1}(5 r(r-\sqrt{r(r+10)+1}+5)-17)}{9(5+r-\sqrt{r(r+10)+1})(1-r+\sqrt{r(r+10)+1})}, \\
& W^{S}(1)=1 / 8(3+r(2+3 r)) .
\end{aligned}
$$

Where the first line uses continuity of social planner objective function on the boundary $\frac{1}{6}(1-r+\sqrt{r(r+10)+1})$, and case 3 above. Direct comparison of the two expressions reveal that $W^{S}(1)>W^{S}\left(\frac{1}{6}(1-r+\sqrt{r(r+10)+1})\right)$ if $r>\frac{2}{15}$. Thus in this range

$$
\phi^{S}=1
$$

Putting the two cases together,

$$
\phi^{S}= \begin{cases}\frac{3}{10}\left(1-2 r+\sqrt{1-4 r-6 r^{2}}\right) & \text { if } 0<r<r_{1} \\ 1 & \text { if } r_{1}<r<\frac{1}{2}\end{cases}
$$

Case 5: $0 \leq \phi<1-\frac{1}{4 r}$.

Here $R^{*}=1$, thus $W^{S}=r$.

Comparison across cases. Next for each $r$, we compare the optimum across cases. Again it is easiest to treat 3 ranges separately

1. $0<\mathrm{r}<\frac{2}{15}$ :

Here we compare the maximum across cases 1, 2, and 4. Case 1 shows that when $0<r<\frac{2}{15}$, maximum is attained at $\phi=\frac{2}{5}$. Case 2 shows that $\phi=\frac{2}{5}$ is also optimal in that range. Thus within cases 1 and $2, \phi=\frac{2}{5}$ is optimal.

In comparing with case 4 , we consider two ranges separately, $r<r_{1}$ and $r>r_{1}$. 
If $r<r_{1}$, in case $4 \phi=\frac{3}{10}\left(1-2 r+\sqrt{1-4 r-6 r^{2}}\right)$ is optimal . Using case $2, W^{S}\left(\frac{2}{5}\right)>$ $W^{S}\left(\frac{3}{10}\left(1-2 r+\sqrt{1-4 r-6 r^{2}}\right)\right)$, thus $\phi^{S}=\frac{2}{5}$ in this range.

If $r>r_{1}$, within the relevant range of case $4, \phi=1$ is optimal. We need to compare the welfare with $\phi=\frac{2}{5}$

$$
\begin{aligned}
W^{S}\left(\frac{2}{5}\right) & =37 / 90 \\
W^{S}(1) & =\frac{1}{8}(r(3 r+2)+3)
\end{aligned}
$$

Direct comparison shows that $W^{S}\left(\frac{2}{5}\right)>W^{S}(1)$ iff $r<r_{l}=\frac{1}{3}\left(2 \sqrt{\frac{7}{15}}-1\right)$. Thus in this range

$$
\phi^{S}=\left\{\begin{array}{cl}
\frac{2}{5} & \text { if } 0<r<r_{l} \\
1 & \text { if } r_{l}<r<\frac{2}{15}
\end{array}\right.
$$

2. $\frac{2}{15}<\mathbf{r}<\frac{1}{4}$ :

Here we compare the maximum across cases 1, 3, and 4. Case 1 shows that when $\frac{2}{15}<r<\frac{1}{4}$, maximum is attained at $\phi=\frac{2}{3}\left(2(1-2 r)-\sqrt{(4 r)^{2}-4 r+1}\right)$. Case 3 shows that $W^{S}\left(\frac{1}{6}(1-r+\sqrt{r(r+10)+1})\right) \geq W^{S}\left(\frac{2}{3}\left(2(1-2 r)-\sqrt{(4 r)^{2}-4 r+1}\right)\right)$, and case 4 shows that $W^{S}(1)>W^{S}\left(\frac{1}{6}(1-r+\sqrt{r(r+10)+1})\right)$ in this region. Thus the maximum is attained at $\phi=1$.

3. $\frac{1}{4}<\mathrm{r}<\frac{1}{2}$ :

Here we compare the maximum across cases 3, 4, and 5 . Case 3 shows that $W^{S}\left(\frac{1}{6}(1-r+\sqrt{r(r+10)+1})\right) \geq W^{S}\left(1-\frac{1}{4 r}\right)=r$, and case 4 shows that $W^{S}(1)>$ $W^{S}\left(\frac{1}{6}(1-r+\sqrt{r(r+10)+1})\right)$ in this region. Thus the maximum is attained at $\phi=$ 1.

Putting all the regions together leads the final result.

$$
\phi^{S}= \begin{cases}\frac{2}{5} & \text { if } 0<r<r_{l} \\ 1 & \text { if } r_{l}<r<\frac{1}{2}\end{cases}
$$


where $r_{l}=\frac{1}{3}\left(2 \sqrt{\frac{7}{15}}-1\right)<\frac{2}{15}$

\section{Proof of Proposition 3}

Proposition 1 shows that for $r<r_{h}, \phi^{*}<1$, while 2 shows that for $r>r_{l}, \phi=1$. It follows that for $r \in\left(r_{l}, r_{h}\right), \phi^{*}<\phi^{S}$, thus bank portfolios are inefficiently opaque.

Next, note that since for $r>r_{l}, \phi^{S}=1$, the socially optimal $R^{*}$ and $D^{*}$ coincide,

$$
R^{*}(1)=\max \left\{\min \left\{1, D^{*}(1)\right\}, 0\right\}=D^{*}(1)=\frac{1+r}{2}
$$

as shown in the main text. Thus $R^{*}(1)$ is monotonically increasing in $r$. On the other hand, given the equilibrium $\phi^{*}$ in equation (A.1), $R^{*}\left(\phi^{*}\right)$ is given by

$$
R^{*}\left(\phi^{*}\right)= \begin{cases}0 & \text { if } r<\frac{1}{4} \\ \frac{-r+\sqrt{r(r+10)+1}+4 \sqrt{2 r(r-\sqrt{r(r+10)+1}+5)+1}-7}{-r+\sqrt{r(r+10)+1}+1} & \text { if } \frac{1}{4}<r \leq r_{z} \\ \frac{D^{*}\left(\phi_{F O C}^{*}\right)}{\phi_{F O C}^{*}}+\frac{1-\phi_{F O C}^{*}}{\phi_{F O C}^{*}}\left(1-\frac{r}{D^{*}\left(\phi_{F O C}^{*}\right)}\right) & \text { if } r_{z}<r<r_{h} \\ \frac{1+r}{2} & \text { if } r_{h}<r<\frac{1}{2}\end{cases}
$$

First, note that $r_{l}=\frac{1}{3}\left(2 \sqrt{\frac{7}{15}}-1\right)<\frac{1}{4}$, thus at $r_{l}, R^{*}\left(\phi^{*}\left(r_{l}\right)\right)<R^{*}(1)=\frac{1+r_{l}}{2}$. Second, evaluate $R^{*}$ at $r_{z}$ as defined in proposition 1 to get $R^{*}\left(\phi^{*}\left(r_{z}\right)\right)<R^{*}\left(1 ; r_{z}\right)=\frac{1+r_{z}}{2}$. Thus $R^{*}\left(\phi^{*}\right) \leq R^{*}(1)$ for $r \in\left(r_{l}, r_{z}\right)$. Third, evaluate $R^{*}$ at $r_{h}$ as defined in proposition 1 to get $R^{*}\left(\phi^{*}\left(r_{h}\right)\right)>R^{*}\left(1 ; r_{h}\right)=\frac{1+r_{h}}{2}$.

Since $R^{*}(1 ; r)=\frac{1+r}{2}$ it is continuous and increasing. Since $\phi^{*}$ is continuous for $r>\frac{1}{4}, R^{*}\left(\phi^{*}\right)$ is continuous for $r>\frac{1}{4}$ as well, including at $r_{z}$. Moreover, $\frac{d R^{*}\left(\phi^{*}(r)\right)}{d r}=R^{*^{\prime}}\left(\phi_{F O C}^{*}(r)\right) \phi_{F O C}^{*^{\prime}}(r)>$ 0 . Along with $R^{*}\left(\phi^{*}\left(r_{z}\right)\right)<R^{*}\left(1 ; r_{z}\right)$ and $R^{*}\left(\phi^{*}\left(r_{h}\right)\right)>R^{*}\left(1 ; r_{h}\right)$, it follows that $R^{*}(\phi *)$ and $R^{*}(1)$ cross once in the interval $\left(r_{z}, r_{h}\right)$, at $r=r_{m}$, such that $R^{*}\left(\phi^{*}\right) \leq R^{*}(1)$ for $r \leq r_{m}$ and $R^{*}\left(\phi^{*}\right)>R^{*}(1)$ for $r>r_{m} \cdot r_{m}$ is defined by $R^{*}\left(\phi^{*}\left(r_{m}\right)\right)=R^{*}\left(1 ; r_{m}\right), r_{m} \approx 0.3287$.

\section{A.2 Full Information Derivations}

In this section we first introduce some useful notation and concepts, as well as a lemma with intermediate results. Then we proceed to the proofs. 
Following the main text, with full information, the portfolio of a bank holding $\phi$ in her project and $(1-\phi)$ in the other bank's project has the following return cumulative distribution

$$
H(z ; \phi)= \begin{cases}\frac{z^{2}}{2 \phi(1-\phi)} & \text { if } z<\phi \\ \frac{1}{1-\phi}\left(z-\frac{\phi}{2}\right) & \text { if } \phi \leq z \leq 1-\phi \\ 1-\frac{(1-z)^{2}}{2 \phi(1-\phi)} & \text { if } z>1-\phi\end{cases}
$$

In this case, each investor I's expected payoff is given by

$$
W_{I}^{F I}=D(1-H(D, \phi))+r H(D, \phi)
$$

each bank $i$ 's expected payoff is given by

$$
W_{i}^{F I}=\int_{D}^{1}\left[(z-D) \frac{\partial H(z, \phi)}{\partial z}\right] d z
$$

while total welfare is given by

$$
W^{S / F I}=\int_{D}^{1}\left[z \frac{\partial H(z, \phi)}{\partial z}\right] d z+r H(D, \phi)
$$

Note that $H(z ; \phi)$ distribution is symmetric around $\phi=\frac{1}{2}$, so we only need to consider the case $0 \leq \phi \leq \frac{1}{2}$. The case $\frac{1}{2} \leq \phi \leq 1$ follows by symmetry. The following lemma characterizes the probability, $R^{* / F I}=H(D, \phi)$, that an investor liquidates the bank at date 1 , as well as the face value of debt, $D^{* / F I}$, as a function of the investor's reservation value, $r$, and of the fraction, $\phi$, that the bank retains of her own project.

Lemma A.2 For any early redemption value $r \in\left(0, \frac{1}{2}\right)$ and any portfolio allocation $(\phi,(1-\phi))$ that banks hold, the probability, $R^{* / F I}$, that an investor liquidates the bank at date 1 , as well as the optimal face value of debt, $D^{* / F I}$, under full information are as follows:

1. $r<\frac{1}{4}$.

(a) $\phi \leq \frac{2 r+2}{5}$, then $D^{* / F I}=\frac{1}{2}(r+1)-\frac{1}{4} \phi \in[\phi,(1-\phi)]$ and $R^{* / F I}=\frac{1}{1-\phi}\left(\frac{1}{2}(r+1)-\frac{3}{4} \phi\right)$.

(b) $\phi>\frac{2 r+2}{5}$, then $D^{* / F I}=\frac{1}{3} r+\frac{1}{3} \sqrt{r^{2}-6 \phi^{2}+6 \phi} \in(r, \phi)$ and $R^{* / F I}=\frac{\left(\frac{1}{3} r+\frac{1}{3} \sqrt{r^{2}-6 \phi^{2}+6 \phi}\right)^{2}}{2 \phi(1-\phi)}$.

2. $r \geq \frac{1}{4}$. 
(a) $\phi \leq \frac{2}{3}(1-r)$, then $D^{* / F I}=\frac{1}{2}(r+1)-\frac{1}{4} \phi \in[\phi,(1-\phi)]$ and $R^{* / F I}=\frac{1}{1-\phi}\left(\frac{1}{2}(r+1)-\frac{3}{4} \phi\right)$.

(b) $\phi>\frac{2}{3}(1-r)$, then $D^{* / F I}=\frac{2}{3} r+\frac{1}{3} \in((1-\phi), 1)$ and $R^{* / F I}=\left(1-\frac{\left(\frac{2}{3}-\frac{2}{3} r\right)^{2}}{2 \phi(1-\phi)}\right)$.

Proof. Since $\phi \leq \frac{1}{2}$, then $\phi \leq 1-\phi$. Thus there are three relevant cases.

Case 1: $D<\phi$. The expected payoff of each investor is given by

$$
W_{I}^{F I}=D\left(1-\frac{D^{2}}{2 \phi(1-\phi)}\right)+r \frac{D^{2}}{2 \phi(1-\phi)}
$$

The first order condition with respect to $D$ yields

$$
\frac{1}{2 \phi(\phi-1)}\left(3 D^{2}-2 r D-2 \phi(1-\phi)\right)=0
$$

which has the following solutions

$$
\begin{aligned}
D_{1 a} & =\frac{1}{3} r-\frac{1}{3} \sqrt{r^{2}-6 \phi^{2}+6 \phi}<0 \\
D_{1 b} & =\frac{1}{3} r+\frac{1}{3} \sqrt{r^{2}-6 \phi^{2}+6 \phi}>0
\end{aligned}
$$

For $D$ to be a feasible solutions, it must verify that $r<D<\phi$. We have that

$$
\phi>\frac{2 r+2}{5} \Rightarrow D_{1 b}<\phi
$$

At the same time, $D_{1 b}<\phi$ is sufficient to imply that $D_{1 b}>r$, as

$$
\phi>\frac{2 r+2}{5} \Rightarrow \phi>\frac{1}{2}-\frac{1}{2} \sqrt{1-2 r^{2}} \Rightarrow D>r
$$

Case 2: $D>(1-\phi)$. The expected payoff of each investor is given by

$$
W_{I}^{F I}=D\left(1-\left(1-\frac{(1-D)^{2}}{2 \phi(1-\phi)}\right)\right)+r\left(1-\frac{(1-D)^{2}}{2 \phi(1-\phi)}\right)
$$

The first order condition with respect to $D$ yields

$$
\frac{1}{2 \phi(\phi-1)}(D-1)(2 r-3 D+1)=0,
$$


which admits the following solution

$$
D_{2}=\frac{2}{3} r+\frac{1}{3}
$$

For $D$ to be a feasible solutions, it is sufficient that it verify that $D>(1-\phi)$, as $(1-\phi)>r$. We have that

$$
D_{2}>(1-\phi) \Longleftrightarrow \phi>\frac{2}{3}(1-r)
$$

Case 3: $D \in[\phi,(1-\phi)]$. The expected payoff of each investor is given by

$$
W_{I}^{F I}=D\left(1-\frac{1}{1-\phi}\left(D-\frac{\phi}{2}\right)\right)+r \frac{1}{1-\phi}\left(D-\frac{\phi}{2}\right)
$$

The first order condition with respect to $D$ yields

$$
\frac{1}{2(\phi-1)}(\phi-2 r+4 D-2)=0
$$

which admits the following solution

$$
D_{3}=\frac{1}{2}(r+1)-\frac{1}{4} \phi
$$

For $D$ to be a feasible solutions, it is sufficient that it verify that $D_{3} \leq(1-\phi), D_{3} \geq \phi$, and $D_{3}>r$. We have that

$$
D_{3} \geq \phi \Leftrightarrow \frac{2}{5}(r+1) \geq \phi
$$

and

$$
D_{3} \leq 1-\phi \Leftrightarrow \frac{2}{3}(1-r) \geq \phi
$$

Note that since $2(1-r)>\phi$, it follows that $D_{3}>r$ as well.

\section{Proof of Proposition 4}

We need to calculate the optimal $\phi$ for a bank $i$. That is, $\phi$ that maximizes

$$
W_{i}^{F I}=\int_{D}^{1}\left[(z-D) \frac{\partial H(z, \phi)}{\partial z}\right] d z
$$


As the optimal face value of debt changes depending on $\phi$ and $r$, we need to consider various cases.

Case 1: $r<\frac{1}{4} \& \phi \leq \frac{2 r+2}{5}$, and $r \geq \frac{1}{4} \& \phi \leq \frac{2}{3}(1-r)$. From Lemma A.2, we have that $D^{* / F I}=\frac{1}{2}(r+1)-\frac{1}{4} \phi$. Substituting into the objective function of bank $i$, we obtain that

$W_{i}^{F I}=\int_{D^{* / F I}}^{1-\phi}\left[\left(z-D^{* / F I}\right) \frac{\partial}{\partial z}\left(\frac{1}{1-\phi}\left(z-\frac{\phi}{2}\right)\right)\right] d z+\int_{1-\phi}^{1}\left[\left(z-D^{* / F I}\right) \frac{\partial}{\partial z}\left(1-\frac{(1-z)^{2}}{2 \phi(1-\phi)}\right)\right] d z$

or

$$
W_{i}^{F I}=\frac{1}{96(1-\phi)}\left(12(r-1)^{2}+12 \phi(r-1)+7 \phi^{2}\right)
$$

Taking the first order condition with respect to $\phi$ yields

$$
\frac{\partial}{\partial \phi} W_{i}^{F I}=\frac{1}{96(\phi-1)^{2}}\left(12 r^{2}-12 r-7 \phi^{2}+14 \phi\right)
$$

Note that the second order condition with respect to $\phi$ yields

$$
\frac{\partial^{2}}{\partial \phi^{2}} W_{i}^{F I}=\frac{1}{48(1-\phi)^{3}}\left(12 r^{2}-12 r+7\right)>0
$$

which implies that any feasible solution of the first order condition would be a local minimum. Thus, to find the value of $\phi$ that maximizes bank $i$ 's objective we need to compare the value of $W_{i}^{F I}$ evaluated at the corners. In particular, for $r<\frac{1}{4}$ we need to compare $W_{i}^{F I}\left(\frac{2 r+2}{5}, D^{* / F I}, r\right)$ and $W_{i}^{F I}\left(0, D^{* / F I}, r\right)$, while for $r \geq \frac{1}{4}$ we need to compare $W_{i}^{F I}\left(\frac{2(1-r)}{3}, D^{* / F I}, r\right)$ and $W_{i}^{F I}\left(0, D^{* / F I}, r\right)$.

Consider first $r<\frac{1}{4}$. Then

$$
W_{i}^{F I}\left(\frac{2 r+2}{5}, D^{* / F I}, r\right)-W_{i}^{F I}\left(0, D^{* / F I}, r\right)=-\frac{1}{240 r-360}\left(30 r^{3}+7 r^{2}-16 r+7\right)>0 .
$$

Thus

$$
\phi^{* / F I}=\frac{2 r+2}{5} .
$$

Consider next $r \geq \frac{1}{4}$. Then

$$
W_{i}^{F I}\left(\frac{2(1-r)}{3}, D^{* / F I}, r\right)-W_{i}^{F I}\left(0, D^{* / F I}, r\right)=-\frac{1}{72(2 r+1)}(18 r-7)(r-1)^{2} .
$$


Thus, if $r<r_{H}=\frac{7}{18}$,

$$
\phi^{* / F I}=\frac{2(1-r)}{3}
$$

and, if $r>r_{H}$,

$$
\phi^{* / F I}=0
$$

Case 2: $r<\frac{1}{4} \& \phi>\frac{2 r+2}{5}$. From Lemma A.2, we have that $D^{* / F I}=\frac{1}{3} r+\frac{1}{3} \sqrt{r^{2}-6 \phi^{2}+6 \phi}$. Substituting into the objective function of the social planner, we obtain that

$$
\begin{aligned}
W_{i}^{F I}= & \int_{D^{* / F I}}^{\phi}\left[\left(z-D^{* / F I}\right) \frac{\partial}{\partial z}\left(\frac{z^{2}}{2 \phi(1-\phi)}\right)\right] d z+\int_{\phi}^{1-\phi}\left[\left(z-D^{* / F I}\right) \frac{\partial}{\partial z}\left(\frac{1}{1-\phi}\left(z-\frac{\phi}{2}\right)\right)\right] d z+ \\
& +\int_{1-\phi}^{1}\left[\left(z-D^{* / F I}\right) \frac{\partial}{\partial z}\left(1-\frac{(1-z)^{2}}{2 \phi(1-\phi)}\right)\right] d z
\end{aligned}
$$

or

$$
W_{i}^{F I}=\frac{1}{2}-\left(\frac{1}{3} r+\frac{1}{3} \sqrt{r^{2}-6 \phi^{2}+6 \phi}\right)+\frac{1}{6} \frac{\left(\frac{1}{3} r+\frac{1}{3} \sqrt{r^{2}-6 \phi^{2}+6 \phi}\right)^{3}}{\phi(1-\phi)}
$$

Taking the first order condition with respect to $\phi$ yields

$$
\frac{\partial}{\partial \phi} W_{i}^{F I}=\frac{2 \phi-1}{\sqrt{r^{2}-6 \phi^{2}+6 \phi}}\left(1+\frac{1}{162 \phi^{2}} \frac{\left(r+\sqrt{r^{2}-6 \phi^{2}+6 \phi}\right)^{2}}{(\phi-1)^{2}}\left(r \sqrt{r^{2}-6 \phi^{2}+6 \phi}+3 \phi^{2}-3 \phi+r^{2}\right)\right)
$$

which has a unique solution of $\phi=\frac{1}{2}$. Note however that the second order condition with respect to $\phi$ evaluated at $\phi=\frac{1}{2}$ yields

$$
\begin{aligned}
\left.\frac{\partial^{2}}{\partial \phi^{2}} W_{i}^{F I}\right|_{\phi=\frac{1}{2}} & =\left.\frac{2 r^{2}+3}{\left(r^{2}-6 \phi^{2}+6 \phi\right)^{\frac{3}{2}}}\right|_{\phi=\frac{1}{2}}+\left.r\left(\frac{\partial}{\partial \phi} \frac{(2 \phi-1)}{162 \phi^{2}} \frac{\left(r+\sqrt{r^{2}-6 \phi^{2}+6 \phi}\right)^{2}}{(\phi-1)^{2}}\right)\right|_{\phi=\frac{1}{2}} \\
& =\left.\frac{2 r^{2}+3}{\left(r^{2}-6 \phi^{2}+6 \phi\right)^{\frac{3}{2}}}\right|_{\phi=\frac{1}{2}}+\left.r\left(\frac{\left(r+\sqrt{r^{2}-6 \phi^{2}+6 \phi}\right)^{2}}{(1-\phi)} \frac{1}{81 \phi^{3}}\right)\right|_{\phi=\frac{1}{2}}>0
\end{aligned}
$$

which implies that the solution $\phi=\frac{1}{2}$ of the first order condition would be a local minimum. Thus, to find the value of $\phi$ that maximizes bank $i$ 's objective we need to compare the value of $W_{i}^{F I}$ evaluated at the corners. In particular, we need $W_{i}^{F I}\left(\frac{2(1-r)}{3}, D^{* / F I}, r\right)$ and 
$W_{i}^{F I}\left(\frac{1}{2}, D^{* / F I}, r\right)$. We show that

$$
W_{i}^{F I}\left(\frac{2(1-r)}{3}, D^{* / F I}, r\right)-W_{i}^{F I}\left(\frac{1}{2}, D^{* / F I}, r\right)>0 .
$$

Thus,

$$
\phi^{* / F I}=\frac{2(1-r)}{3}
$$

Case 3: $r \geq \frac{1}{4} \& \phi>\frac{2}{3}(1-r)$. From Lemma A.2, we have that $D^{* / F I}=\frac{2}{3} r+\frac{1}{3}$. Substituting into the objective function of of bank $i$, we obtain that

$$
W_{i}^{F I}=\int_{D^{* / F I}}^{1}\left(\left(z-D^{* / F I}\right) \frac{\partial}{\partial z}\left(1-\frac{(1-z)^{2}}{2 \phi(1-\phi)}\right)\right) d z
$$

or

$$
W_{i}^{F I}=\frac{1}{6 \phi(\phi-1)}\left(\frac{2}{3} r-\frac{2}{3}\right)^{3}
$$

Taking the first order condition with respect to $\phi$ yields

$$
\frac{\partial}{\partial \phi} W_{i}^{F I}=\frac{4}{81 \phi^{2}(\phi-1)^{2}}(2 \phi-1)(1-r)^{3} \leq 0
$$

Note that the second order condition with respect to $\phi$ yields

$$
\frac{\partial^{2}}{\partial \phi^{2}} W_{i}^{F I}=\frac{8}{81 \phi^{3}(1-\phi)^{3}}(1-r)^{3}\left(3 \phi^{2}-3 \phi+1\right)>0
$$

Thus, bank $i$ 's expected payoff is always decreasing in this case.

Thus, the derivations in Case 1 and Case 2 imply that for $r<\frac{1}{4}$ bank $i$ 's expected payoff is maximized at $\phi^{* / F I}=\min \left\{\frac{2 r+2}{5}, \frac{2(1-r)}{3}\right\}$. Similarly, the derivations in Case 1 and Case 3 imply that for $r \geq \frac{1}{4}$ bank $i$ 's expected payoff is maximized at $\phi^{* / F I}=\min \left\{\frac{2 r+2}{5}, \frac{2(1-r)}{3}\right\}$ if $r \leq r_{H}$ and at $\phi^{* / F I}=0$ if $r>r_{H}$.

Note that for any portfolio allocation $(\phi, 1-\phi)$ that is an equilibrium, the portfolio allocation $(1-\phi, \phi)$ is also an equilibrium. This follows from the symmetry of the banks' portfolio return distribution in the full information case. We will work with $(1-\phi, \phi)$ to make it comparable with the analysis with incomplete information. Thus, bank $i$ 's expected payoff is maximized at $\phi^{* / F I}=\max \left\{\frac{3-2 r}{5}, \frac{21+2 r}{3}\right\}$ if $r \leq r_{H}$ and at $\phi^{* / F I}=1$ if $r>r_{H}$. 


\section{Proof of Proposition 5}

We need to calculate the optimal $\phi$ for the social planner. That is, $\phi$ that maximizes

$$
W^{S / F I}=\int_{D}^{1}\left[z \frac{\partial H(z, \phi)}{\partial z} d z\right]+r H(D, \phi) .
$$

As the optimal face value of debt changes depending on $\phi$ and $r$, we need to consider various cases.

Case 1: $r<\frac{1}{4} \& \phi \leq \frac{2 r+2}{5}$, and $r \geq \frac{1}{4} \& \phi \leq \frac{2}{3}(1-r)$. From Lemma A.2, we have that $D^{* / F I}=\frac{1}{2}(r+1)-\frac{1}{4} \phi$. Substituting into the objective function of the social planner, we obtain that

$$
\begin{aligned}
W^{S / F I}= & \int_{D^{* / F I}}^{1-\phi}\left[z \frac{\partial}{\partial z}\left(\frac{1}{1-\phi}\left(z-\frac{\phi}{2}\right)\right)\right] d z+\int_{1-\phi}^{1}\left[z \frac{\partial}{\partial z}\left(1-\frac{(1-z)^{2}}{2 \phi(1-\phi)}\right)\right] d z \\
& +r \frac{1}{1-\phi}\left(D^{* / F I}-\frac{\phi}{2}\right)
\end{aligned}
$$

or

$$
W^{S / F I}=\frac{1}{96(1-\phi)}\left(36 r^{2}-60 r \phi+24 r+13 \phi^{2}-36 \phi+36\right) .
$$

Note that the second order condition with respect to $\phi$ yields

$$
\frac{\partial^{2}}{\partial \phi^{2}} W^{S / F I}=\frac{1}{48(1-\phi)^{3}}\left(36 r^{2}-36 r+13\right)>0,
$$

which implies that any feasible solution of the first order condition would be a local minimum. Thus, to find the value of $\phi$ that maximizes welfare we need to compare the value of $W^{S / F I}$ evaluated at the corners. In particular, for $r<\frac{1}{4}$ we need to compare $W^{S / F I}\left(\frac{2 r+2}{5}, D^{* / F I}, r\right)$ and $W^{S / F I}\left(0, D^{* / F I}, r\right)$, while for $r \geq \frac{1}{4}$ we need to compare $W^{S / F I}\left(\frac{2(1-r)}{3}, D^{* / F I}, r\right)$ and $W^{S / F I}\left(0, D^{* / F I}, r\right)$.

Consider first $r<\frac{1}{4}$. Then

$$
W^{S / F I}\left(\frac{2 r+2}{5}, D^{* / F I}, r\right)-W^{S / F I}\left(0, D^{* / F I}, r\right)=-\frac{1}{240 r-360}\left(90 r^{3}+13 r^{2}-64 r+13\right)
$$


Thus, if $r<r_{L} \simeq 0.23$,

$$
\phi^{S / F I}=\left(\frac{2 r+2}{5}\right)
$$

and, if $r>r_{L}$,

$$
\phi^{S / F I}=0
$$

Consider next $r \geq \frac{1}{4}$

$$
W^{S / F I}\left(\frac{2(1-r)}{3}, D^{* / F I}, r\right)-W^{S / F I}\left(0, D^{* / F I}, r\right)=-\frac{1}{72(2 r+1)}(54 r-13)(r-1)^{2}<0
$$

Thus

$$
\phi^{S / F I}=0
$$

Case 2: $r<\frac{1}{4} \& \phi>\frac{2 r+2}{5}$. From Lemma A.2, we have that $D^{* / F I}=\frac{1}{3} r+\frac{1}{3} \sqrt{r^{2}-6 \phi^{2}+6 \phi}$.

Substituting into the objective function of the social planner, we obtain that

$$
\begin{aligned}
W^{S / F I}= & \int_{D^{* / F I}}^{\phi}\left[z \frac{\partial}{\partial z}\left(\frac{z^{2}}{2 \phi(1-\phi)}\right)\right] d z+\int_{\phi}^{1-\phi}\left[z \frac{\partial}{\partial z}\left(\frac{1}{1-\phi}\left(z-\frac{\phi}{2}\right)\right)\right] d z+ \\
& +\int_{1-\phi}^{1}\left[z \frac{\partial}{\partial z}\left(1-\frac{(1-z)^{2}}{2 \phi(1-\phi)}\right)\right] d z+r \frac{D^{* / F I 2}}{2 \phi(1-\phi)}
\end{aligned}
$$

or

$$
W^{S / F I}=\frac{1}{6 \phi(1-\phi)}\left(-3 \phi^{2}+3 \phi-2\left(\frac{1}{3} r+\frac{1}{3} \sqrt{r^{2}-6 \phi^{2}+6 \phi}\right)^{3}+3 r\left(\frac{1}{3} r+\frac{1}{3} \sqrt{r^{2}-6 \phi^{2}+6 \phi}\right)^{2}\right)
$$

Taking the first order condition with respect to $\phi$ yields

$$
\frac{\partial}{\partial \phi} W^{S / F I}=\frac{(2 \phi-1)}{162 \phi^{2}} \frac{\left(r+\sqrt{r^{2}-6 \phi^{2}+6 \phi}\right)}{(\phi-1)^{2} \sqrt{r^{2}-6 \phi^{2}+6 \phi}}(\left(6 \phi-6 \phi^{2}+5 r^{2}\right) \underbrace{\left(\sqrt{6 \phi-6 \phi^{2}+r^{2}}-r\right)}_{>0}+10 r^{3}) \leq 0 .
$$


Note that the second order condition with respect to $\phi$ yields

$$
\begin{aligned}
& \frac{\partial^{2}}{\partial \phi^{2}} W^{S / F I}=\underbrace{\frac{1}{27 \phi^{2}(\phi-1)^{2}\left(r^{2}+6 \phi(1-\phi)\right)^{\frac{3}{2}}}}_{>0} \times \\
& \underbrace{(\underbrace{\left(10 \phi^{2}-10 \phi+5\right)}_{>0} r^{4}+\underbrace{\left(216 \phi^{3}-108 \phi^{4}-153 \phi^{2}+45 \phi\right)}_{>0} r^{2}+\underbrace{\left(18 \phi^{4}-36 \phi^{3}+18 \phi^{2}\right)}_{>0})}_{>0} \\
& +\underbrace{\frac{3(2 \phi-1)^{2} 10 r^{4}}{162 \phi^{2}(\phi-1)^{2}} \frac{1}{\left(r^{2}-6 \phi^{2}+6 \phi\right)^{\frac{3}{2}}}+\frac{10}{81} \frac{r^{4}}{\phi^{3}(1-\phi)^{3}}\left(3 \phi^{2}-3 \phi+1\right) \frac{1}{\sqrt{r^{2}-6 \phi^{2}+6 \phi}}}_{>0} \\
& +\underbrace{\frac{10}{81} \frac{r^{3}}{\phi^{3}(1-\phi)^{3}}\left(3 \phi^{2}-3 \phi+1\right)}_{>0}
\end{aligned}
$$

which implies that any feasible solution of the first order condition would be a local minimum.

Thus, the total welfare is always decreasing in this case.

Case 3: $r \geq \frac{1}{4} \& \phi>\frac{2}{3}(1-r)$. From Lemma A.2, we have that $D^{* / F I}=\frac{2}{3} r+\frac{1}{3}$.

Substituting into the objective function of the social planner, we obtain that

$$
W^{S / F I}=\int_{D^{* / F I}}^{1}\left(z \frac{\partial}{\partial z}\left(1-\frac{(1-z)^{2}}{2 \phi(1-\phi)}\right)\right) d z+r\left(1-\frac{\left(1-D^{* / F I}\right)^{2}}{2 \phi(1-\phi)}\right)
$$

or

$$
W^{S / F I}=\frac{1}{81 \phi(\phi-1)}\left(10 r^{3}-30 r^{2}+81 r \phi^{2}-81 r \phi+30 r-10\right) .
$$

Taking the first order condition with respect to $\phi$ yields

$$
\frac{\partial}{\partial \phi} W^{S / F I}=\frac{10}{81 \phi^{2}(\phi-1)^{2}}(1-2 \phi)(r-1)^{3} \leq 0 .
$$

Note that the second order condition with respect to $\phi$ yields

$$
\frac{\partial^{2}}{\partial \phi^{2}} W^{S / F I}=\frac{20}{81 \phi^{3}(1-\phi)^{3}}(1-r)^{3}\left(3 \phi^{2}-3 \phi+1\right) \geq 0
$$

Thus, the total welfare is always decreasing in this case.

Thus, the derivations in Case 1 and Case 2 imply that for $r<\frac{1}{4}$ social welfare is maximized 
at $\phi^{S / F I}=\frac{2 r+2}{5}$ if $r \leq r_{L}$ and at $\phi^{S / F I}=0$ if $r>r_{L}$. Similarly, the derivations in Case 1 and Case 3 imply that for $r \geq \frac{1}{4}$ social welfare is maximized at $\phi^{S / F I}=0$.

Note that for any portfolio allocation $(\phi, 1-\phi)$ that is an optimum, the portfolio allocation $(1-\phi, \phi)$ is also an optimum. This follows from the symmetry of the banks' portfolio return distribution in the full information case. We will work with $(1-\phi, \phi)$ to make it comparable with the analysis with incomplete information. Thus,social welfare is maximized at $\phi^{* / F I}=\frac{3-2 r}{5}$ if $r \leq r_{L}$ and at $\phi^{* / F I}=1$ if $r>r_{L}$.

\section{Proof of Proposition 6}

The first of the part of the proposition simply follows as a corollary of Proposition 4 and of Proposition 5.

For the second part of the proposition, we need to show that for any $r \in\left(r_{L}, r_{H}\right)$, then $R^{* / F I}\left(\phi^{* / F I}\right) \leq R^{* / F I}(1)$.

Since $r<r_{H}$, we know from Proposition 4 that $\phi^{* / F I}=\min \left\{\frac{2 r+2}{5}, \frac{2(1-r)}{3}\right\}$, and from Lemma A.2 we have that

$$
R^{* / F I}\left(\phi^{* / F I}\right)= \begin{cases}\frac{1}{1-\frac{2 r+2}{5}}\left(\frac{1}{2}(r+1)-\frac{3}{4} \times \frac{2 r+2}{5}\right) & \text { if } r \in\left(r_{L}, \frac{1}{4}\right] \\ \frac{1}{1-\frac{2(1-r)}{3}}\left(\frac{1}{2}(r+1)-\frac{3}{4} \times \frac{2(1-r)}{3}\right) & \text { if } r \in\left(\frac{1}{4}, r_{H}\right)\end{cases}
$$

Because of symmetry we also have that

$$
R^{* / F I}\left(\phi^{* / F I}=1\right)=R^{* / F I}\left(\phi^{* / F I}=0\right)
$$

or

$$
R^{* / F I}(1)=\frac{1}{1-0}\left(\frac{1}{2}(r+1)-\frac{3}{4} \times 0\right)=\frac{1}{2}(r+1) .
$$

It is straightforward to show that

$$
R^{* / F I}\left(\phi^{* / F I}\right)-R^{* / F I}(1)<0
$$


Indeed

$$
R^{* / F I}\left(\phi^{* / F I}\right)-R^{* / F I}(1)= \begin{cases}-\frac{1}{4 r-6}\left(2 r^{2}+r-1\right)<0 & \text { if } r \in\left(r_{L}, \frac{1}{4}\right] \\ -\frac{1}{4 r+2}\left(2 r^{2}-3 r+1\right)<0 & \text { if } r \in\left(\frac{1}{4}, r_{H}\right)\end{cases}
$$

